\title{
Rules versus Discretion: A Reconsideration
}

\begin{abstract}
In this paper, I evaluate the relative merits of rules versus discretion in making monetary policy, from both empirical and theoretical perspectives. Empirically, I argue that in the 2009-10 period, the Federal Open Market Committee aimed for a slow recovery, in large part because its judgments about appropriate monetary policy were unduly influenced by the Taylor rule (which was seen as a good approximation of its pre-2007 reaction function). Theoretically, I use the delegation framework of Bengt Holmström (1984) to show that, as long as the central bank's inflation bias is sufficiently small, it is socially desirable to give the central bank discretion so that it can respond effectively to inflation shocks that cannot be encoded into predetermined rules.
\end{abstract}

$\mathrm{n}$ this paper, I compare two kinds of monetary policy regimes. The first kind is a rule regime, in which the policymaker sets the central bank's instruments (asset purchases or the short-term interest rate) according to a predetermined function of publicly observable variables. The second kind features complete discretion, so that the policymaker can make whatever instrument choice is seen as being appropriate at that point in time. During the past 40 years, a broad consensus has developed among academic macroeconomists that policymakers' choices should closely adhere to predetermined rules. ${ }^{1}$ This consensus can be traced back to two key papers. From a theoretical perspective, Finn Kydland and Edward Prescott (1977)

1. John Taylor (1993, p. 197) writes, "If there is anything about which modern macroeconomics is clear however-and on which there is substantial consensus-it is that policy rules have major advantages over discretion in improving economic performance." His words go back nearly a quarter century but are probably now even more widely viewed as being true. Thus, three Nobel laureates (Hansen and others 2016) joined Taylor in signing a letter in support of Congress's requiring the Federal Reserve to explain any deviations from the Taylor rule. Rules enjoy considerably less support among those who actually have the responsibility of making policy, as evidenced in an open letter from Chair Janet Yellen to Representatives Nancy Pelosi and Paul Ryan (Yellen 2015). But even she relies heavily on variants of the Taylor rule when it comes to thinking about how to structure policy responses to shocks (Yellen 2016). 
showed that nominal rigidities created a challenging time consistency problem for monetary policymakers. Given this problem, it was welfare-improving to require monetary policymakers to follow a predetermined rule. From a practical perspective, John Taylor (1993) demonstrated that the Federal Reserve's monetary policy choices could, in fact, be well approximated with a simple feedback rule (from publicly observed economic conditions to interest rates), and that this rule was associated with good macroeconomic outcomes. These two papers have had enormous influence in both academic and policy circles. Most academic papers in monetary economics treat policymakers as mere error terms in a prespecified feedback rule. And most modern central bank staffs model their policymaker bosses in exactly the same way.

In this paper, I reevaluate the relative merits of discretion versus rules from both empirical and theoretical perspectives. The empirical problem with rules is that monetary policymakers or their overseers are forced to choose rules based in large part on their prior performance. Unfortunately, the rule's performance may deteriorate sharply if conditions change sufficiently. I argue that the Federal Open Market Committee's (FOMC's) 2009-10 decisions can be seen as an important illustration of this general problem with rules.

To make this argument, I use information in the transcripts from 2009-10 FOMC meetings (shortly after the end of the Great Recession in June 2009). ${ }^{2}$ I document that the FOMC pursued a relatively slow recovery, during which unemployment and inflation were anticipated to take at least six years to return to their long-run levels. ${ }^{3}$ I trace this lack of aggressiveness to the FOMC's treating its staff's forecast for unemployment and inflation as an approximate target for appropriate monetary policy. This forecast was based on the presumption that the committee would use the Taylor rule ${ }^{4}$ - seen as a good approximation of the FOMC's pre-2007 reaction

2. The FOMC publicly releases transcripts of its meetings, along with supporting staff materials, with a five- to six-year lag. The transcript from the December 2010 meeting is the latest one that has been released so far.

3. I served on the FOMC from October 2009 through October 2015. Throughout the time frame from November 2009 to November 2010, I believed that, under appropriate monetary policy, inflation would return to 2 percent or even slightly above within two to three years. However, I thought that inflationary pressures were considerably stronger than most of my colleagues on the FOMC, and so favored less monetary accommodation than most of them.

4. The term "Taylor rule" is used to refer to a wide class of monetary policy rules. Throughout the paper, I use the term to refer specifically to the interest rate rule originally described by Taylor (1993), or to the FOMC staff's version of that rule (which uses Okun's law to substitute an unemployment gap for the Taylor rule's output gap), subject to a lower bound of 0.25 percent. 
function - as its guide for removing accommodation. It follows that the FOMC's desire for a slow recovery was based on this same presumption that its exit strategy would be shaped by the Taylor rule. ${ }^{5}$

The empirical analysis does leave open the possibility that there is some other rule out there, yet to be found, that would dominate discretion. In the second part of the paper, I explore this question theoretically, using the delegation model of Bengt Holmström (1984). The main trade-off in the theoretical framework is that the central bank may desire a different level of inflation than does society, but the central bank also has information about the future course of inflation that is impossible to write into a rule. Here, I have in mind the central bank's ability to see a large number of possible factors, with time-varying factor loadings, that help it forecast inflation. For example, suppose a large European financial institution suddenly closes three investment funds. ${ }^{6}$ How will the central bank respond to this shock? The appropriate response will depend on a host of details that would be hard to write into any predetermined rule.

In the context of the model, I compare two possible institutional setups: discretion, under which the central bank can choose any level of monetary accommodation that it wishes; and a rule, under which the central bank's decision is a fixed function of some publicly observable information. ${ }^{7}$ The benefit of the framework of discretion is that the central bank has the ability to offset shocks that cannot be encoded into a rule, but would otherwise generate highly variable inflation. The cost of discretion is that inflationary outcomes will be systematically different from the socially optimal level, because of the central bank's inflation bias. Correspondingly, I show that, in terms of ex ante welfare, discretion generates better outcomes for society as long as the central bank has a sufficiently small inflation bias relative to the magnitude of nonrulable inflationary shocks. (Here, I use two notions of ex ante welfare: quadratic loss; and a min-max robustness criterion, as developed by Lars Peter Hansen and Thomas J. Sargent in 2007.) I use evidence from the past two decades to argue that the Federal Reserve does not have a material proinflation bias (meaning, at most, 0.25 percent). ${ }^{8}$

5. I made a similar argument in Kocherlakota (2015a).

6. Readers will recognize this as a description of BNP Paribas's decision on August 9, 2007.

7. My terminology mirrors that of Kydland and Prescott (1977). However, others prefer a broader notion of rules: What I call discretion in this paper, Ben Bernanke has called a rule (da Costa 2015).

8. See Kocherlakota (2015b) for a related discussion. 
The empirics and the theory both suggest that, contrary to conventional wisdom, monetary policy rules impede central bank performance. Central banks will achieve better outcomes if they are given discretion-that is, if, on an ongoing basis, they can make choices based on all available information to keep inflation or employment close to target. It is particularly important that this recommendation does hinge on the inflationary bias of the central bank being small. This seems to be an accurate description of the Federal Reserve in the past 20 years, but I provide no guidance about how to ensure that it will continue to be true in the future.

My analysis is closely related to much prior work. In terms of the empirics, during the 2009-10 period, many observers critiqued the FOMC for providing insufficient levels of accommodation. ${ }^{9}$ My contribution here is that my use of internal committee documents (only released over the last couple of years) sheds new light on how the FOMC's precrisis framework contributed to this underprovision of accommodation. In terms of the theory, Matthew Canzoneri (1985) illustrates a similar tension between central bank bias and central bank private information. Lars Svensson (2003) makes points that are similar to mine about how discretion allows central banks to use judgment to achieve better macroeconomic outcomes. ${ }^{10}$

\section{The Not-So-Great Recovery and the Taylor Rule}

In this section, I discuss the FOMC's actions during the beginning of the recovery from the 2007-09 Great Recession. The main argument unfolds in three steps. I first show that the FOMC was aiming for a slow recovery in both inflation and unemployment. I next show that the FOMC's projected slow recovery was, in fact, close to the FOMC staff's forecast for unemployment and inflation-in essence, the FOMC was treating its staff's forecast as its target for monetary policy. The staff forecast assumed that the committee's decisions about the timing of the initial federal funds rate increase, and subsequent increases, would be based on the Taylor rule, because it was viewed as providing a good approximation of the

9. For example, see Gagnon (2009).

10. Throughout the paper, I compare outcomes under rules to outcomes under complete discretion, so that the central bank can choose any amount of accommodation. In a dynamic version of the problem that I study, Athey, Atkeson, and Kehoe (2005) prove that the optimal delegation game is either a rule or has bounded discretion (which is what I term constrained discretion). In their benchmark parametric example, they prove that, as the central bank's private information becomes increasingly large, the optimal delegation game converges to one without any constraint on discretion. 
committee's pre-2007 reaction function. I conclude that the FOMC's desire for a slow recovery was grounded in the fact that it treated its staff's model of its pre-2007 reaction function - that is, the Taylor rule — as a guide to the appropriate normalization of monetary policy.

I then use William Brainard's (1967) policy uncertainty framework to assess the possible influence of concerns about policy ineffectiveness on the Federal Reserve's decisions. I argue that these concerns should have led to more aggressive policy choices than those made by the FOMC. I discuss the parallels between the 2009-10 FOMC decisions and the 1929-30 policy errors discussed by Karl Brunner and Allan Meltzer (1968). I close the section by arguing that the FOMC's continued reliance on variants of the Taylor rule seems likely to lead to slow recoveries from future recessions.

\section{I.A. The Summary of Economic Projections}

My discussion relies heavily on the FOMC's Summary of Economic Projections (SEP). Since 2007, the FOMC's participants (who include all 12 presidents of the regional Federal Reserve banks and the members of the Federal Reserve's Board of Governors) have submitted their forecasts for key macroeconomic variables four times a year. These submissions make up the $S E P$. It is particularly important that, as the description of the $S E P$ clearly states, a given participant's forecast is "based ... on each participant's assumptions about factors likely to affect economic outcomes, including his or her assessment of appropriate monetary policy. 'Appropriate monetary policy' is defined as the future path of policy that the participant deems most likely to foster outcomes for economic activity and inflation that best satisfy his or her interpretation of the Federal Reserve's dual objectives of maximum employment and stable prices." 11 A given participant's assessment of the appropriate stance of monetary policy may well differ from his or her forecast of what the committee would actually do. As a result, these so-called projections should not be seen as reflecting participants' forecasts for the actual course of the economy. Rather, beyond the usual one- to two-year lag associated with monetary policy, a participant's projection is best viewed as a description of his or her monetary policy goals for the changes in the relevant macroeconomic variables.

After the relevant meeting, the FOMC releases summary statistics from the $S E P$ to the public. However, when the FOMC releases the meeting

11. This description of the $S E P$, from the November 2009 FOMC meeting minutes, can be found here: https://www.federalreserve.gov/monetarypolicy/fomcminutes20091104ep.htm. 
Table 1. FOMC's Median Fourth Quarter Projections for the Unemployment Rate, 2009-10

\begin{tabular}{ccccc}
\hline Year & Current & $\begin{array}{c}\text { Two years } \\
\text { ahead }\end{array}$ & $\begin{array}{c}\text { Three years } \\
\text { ahead }\end{array}$ & Long run \\
\hline 2009 & 10 & 8.3 & 7.0 & 5.0 \\
2010 & 9.7 & 8.0 & 7.1 & 5.3 \\
\hline
\end{tabular}

Source: FOMC (2009c, 2010d).

transcript (more than five years after the meeting), it also releases the full set of SEP submissions. The full SEPs provide valuable information, given that they link participants' relatively detailed and standardized assessments of the economy and policy with their forecasts. ${ }^{12}$ I make extensive use of all this public information. Hence, my discussion focuses on the SEP from the years 2009-10, since the full SEPs from later years have not been released. In addition, I restrict my attention to the fourth quarter $S E P$ s from those years because they have a longer forecast horizon than $S E P$ s from earlier in the year.

\section{I.B. The FOMC's Limited Ambitions}

According to the Federal Reserve Act, the FOMC is charged by Congress to make monetary policy that will promote price stability and maximum employment. The committee has translated the objective of price stability into a goal of 2 percent inflation for personal consumption expenditures (PCE). With respect to the objective of maximum employment, it tracks progress using a number of metrics, but it tends to put the most weight on the unemployment rate. In principle, the two mandated objectives could conflict with one another, and this conflict did shape some participants' SEP submissions. However, most saw no conflict between the two goals during this time frame: Inflation was expected to be too low, and unemployment was expected to be too high.

Table 1 documents the intentions of the median FOMC participant in the fourth quarters of 2009 and 2010 for the change in the unemployment rate over the medium term. The median FOMC participant believed that, under appropriate monetary policy, the unemployment rate would fall to

12. Unfortunately, the submissions remain anonymous for another five years. As a result, it is impossible to link a participant's submissions at one meeting to his or her submissions at another until a decade after both meetings. 
Table 2. FOMC's Median Fourth Quarter Projections for PCE Inflation, 2009-10

\begin{tabular}{ccccc}
\hline Year & Current & $\begin{array}{c}\text { Two years } \\
\text { ahead }\end{array}$ & $\begin{array}{c}\text { Three years } \\
\text { ahead }\end{array}$ & Long run \\
\hline 2009 & 1.1 & 1.5 & 1.5 & 2.0 \\
2010 & 1.3 & 1.5 & 1.5 & 2.0 \\
\hline
\end{tabular}

Source: FOMC (2009c, 2010d).

about 8 percent in two years and to about 7 percent in three years. Obviously, these figures were well below the unemployment rate that prevailed at the time that the forecasts were made. At the same time, however, the committee was aiming for a relatively slow recovery in employment, in the sense that the unemployment rate in three years' time remained well above its long-run level.

As noted above, however, the FOMC has two objectives. It could be that the committee was aiming for a measured recovery in the unemployment rate in order to guard against inflation. Table 2 documents the committee's intentions in the fourth quarters of 2009 and 2010 for the change in the PCE inflation rate over the medium term. The median FOMC participant believed that, under appropriate monetary policy, the inflation rate would rise to about 1.5 percent in both two years and three years, well short of the median long-run target of 2 percent. In both years, and at both horizons, at most one FOMC participant saw inflation above 2 percent as appropriate. In 2009 and 2010, the FOMC was aiming to use its monetary policy tools to foster a recovery that would return both inflation and unemployment to their long-run levels relatively slowly.

The FOMC did not adopt an official long-run target until January 2012. Even so, in 2009 and 2010, no FOMC participant believed that inflation should be above 2 percent in the long run. However, in 2009, five participants said that it would be appropriate for inflation to converge to less than 2 percent in the long run. One year later, that number had grown to seven participants. Perhaps surprisingly, the various median projections remain little changed if we focus only on those dovish participants who view a long-run inflation rate of 2 percent as appropriate.

These forecasts only extend out three years. However, the SEPs also ask the FOMC participants whether the economy's convergence with the committee's long-run goals would take more or less time than five or six years. In November 2009, only one participant saw this convergence taking place in fewer than five years. More than half believed that it would take longer than six years. In November 2010, only two participants saw this 
convergence taking place in fewer than five years, while several believed that it would take longer than six years.

\section{I.C. Why Were the FOMC's Aims So Modest?}

The FOMC's stated goals for monetary policy are to return inflation to its long-run target and to return unemployment to its long-run level. As Ben Bernanke put it in 2015, when he was no longer chair of the FOMC: "The Fed has a rule. The Fed's rule is that we will go for a two percent inflation rate. We will go for the natural rate of unemployment. We will put equal weight on those two things. We will give you information about our projection, our interest rates. That is a rule" (Bernanke 2015). This is presumably intended to be a description of forecast targeting, along the lines discussed by Svensson (1997), among others. But, as with other descriptions of the Federal Reserve's monetary policy objectives, Bernanke's does not specify any target horizon. As a result, his description is equally consistent with a plan to return inflation to target over 1 year, 2 years, or 20 years. Put another way, it is equally consistent with the FOMC's using the 1993 iteration of the Taylor rule or instead using a version of the rule with coefficients of 10,000 on the inflation gap and output gap (which would return unemployment and inflation to desired levels much more rapidly). The FOMC's framework simply provides no judgment about the appropriate pace of the recovery of inflation and unemployment from an adverse shock.

In this subsection, I argue that in 2009 and 2010, the FOMC filled this vacuum by treating its staff's forecast as its target for appropriate monetary policy. This forecast was based on the Taylor rule (as a good stand-in for the FOMC's pre-2007 reaction function). Hence, the FOMC was essentially using the Taylor rule as its monetary policy rule, especially in its determination of the appropriate timing and pace of liftoff from the effective lower bound.

To make this case, I turn next to the FOMC staff's forecasts for the economy. ${ }^{13}$ The staff based its forecasts on the assumption that the committee would begin to raise interest rates around the time implied by the Taylor

13. Many wonder about the influence of the chair on the staff's forecast. My own perspective is well summarized by these words from then governor Laurence H. Meyer's classic (1998) speech, "Come with Me to the FOMC": "Whose forecast is this? Is it really the staff's independent judgment, or is it the chairman's forecast that the staff has dutifully adopted as their own? I wondered about this myself before joining the Board. I can only talk about my experience, though I have, as you might guess, taken some interest in the workings and history of the FOMC, and will over time develop a better understanding of past practice. But it is very clear today that the forecast is the staff's independent judgment." 
Table 3. FOMC Staff's Fourth Quarter Projections for the Unemployment Rate, 2009-10

\begin{tabular}{ccccccc}
\hline Year & Current & $\begin{array}{c}\text { One year } \\
\text { ahead }\end{array}$ & $\begin{array}{c}\text { Two years } \\
\text { ahead }\end{array}$ & $\begin{array}{c}\text { Three years } \\
\text { ahead }\end{array}$ & $\begin{array}{c}\text { Four years } \\
\text { ahead }\end{array}$ & $\begin{array}{c}\text { Five years } \\
\text { ahead }\end{array}$ \\
\hline 2009 & 10.1 & 9.5 & 8.2 & 6.1 & 4.9 & 4.7 \\
2010 & 9.7 & 9.0 & 7.9 & 7.1 & 6.1 & 5.2 \\
\hline
\end{tabular}

Source: Federal Reserve Board staff (2009a, 2010a).

Table 4. FOMC Staff's Fourth Quarter Projections for PCE Inflation, 2009-10

\begin{tabular}{ccccccc} 
Year & Current & $\begin{array}{c}\text { One year } \\
\text { ahead }\end{array}$ & $\begin{array}{c}\text { Two years } \\
\text { ahead }\end{array}$ & $\begin{array}{c}\text { Three years } \\
\text { ahead }\end{array}$ & $\begin{array}{c}\text { Four years } \\
\text { ahead }\end{array}$ & $\begin{array}{c}\text { Five years } \\
\text { ahead }\end{array}$ \\
\hline 2009 & 1.1 & 1.4 & 1.0 & 1.2 & 1.4 & 1.6 \\
2010 & 1.3 & 1.1 & 1.1 & 1.2 & 1.4 & 1.6
\end{tabular}

Source: Federal Reserve Board staff (2009a, 2010a).

rule, and then follow the rule thereafter. ${ }^{14}$ The staff made this assumption on empirical grounds; its analysis suggested that the rule had served as a good approximation for the committee's precrisis behavior. This led to the outlooks for the fourth quarters of 2009 and 2010 given in tables 3 and 4.

As with the FOMC's projections given in tables 1 and 2, the staff's outlook features a slow decline in the unemployment rate, coupled with a slow increase in the inflation rate (back to, in this case, the staff's assumed target of 2 percent). There are some slight differences-for example, the FOMC is aiming for a somewhat faster return of inflation to target than is reflected in the staff's outlook. However, overall, the FOMC's monetary policy target closely tracks the staff's forecast based on the Taylor rule.

The November 2009 and 2010 SEPs do report that a number of FOMC participants believe that, under appropriate monetary policy, the federal funds rate should rise more rapidly than is expected by the staff (FOMC 2009c; 2010d, pp. 18-19). But only a couple of these participants (5 and 16 in 2009) explicitly suggest deviating from the Taylor rule. Instead, the participants seem to arrive at their preferred interest rate path by plugging sub-2 percent long-run targets for inflation or stronger inflation

14. See footnote 4 in Federal Reserve Board staff (2009a, p. I-20), and footnote 4 in Federal Reserve Board staff (2010a, p. 30). In October 2010, the staff assumed that the FOMC held the federal funds rate at zero slightly longer than would be implied by the Taylor (1993) rule. 
and unemployment outlooks into the same rule used by staff. ${ }^{15}$ Also, as I noted above, those participants with 2 percent inflation targets also prefer a slow recovery that is close to the staff's benchmark (Taylor rule-based) outlook.

Why did the Taylor rule imply such a slow recovery? This rule is designed to eliminate inflation gaps (between current inflation and a 2 percent target) and output or unemployment gaps. However, the rule constrains the size of the FOMC's response to these gaps; in particular, it precludes the FOMC from rapidly cutting interest rates until all gaps are eliminated. ${ }^{16}$ In this sense, the Taylor rule represents a constraint on the FOMC's interest rate response to inflation and activity gaps.

Mathematically, one can think of the Taylor rule as being the result of the FOMC putting some weight on an implicit objective to keep the federal funds rate close to its historically normal level. To be more concrete, suppose that the central bank has a quadratic loss function, with weight on both inflation gaps and interest rate gaps:

$$
-\left(\pi-\pi^{*}\right)^{2}-\lambda\left(i-i^{*}\right)^{2}
$$

Suppose as well that the current inflation rate is well approximated by an affine function of the current interest rate:

$$
\pi=\alpha-\beta i
$$

Then the bank's optimal interest rate choice would be to set the interest rate equal to

$$
\left(\pi-\pi^{*}\right) \beta=\lambda\left(i-i^{*}\right),
$$

15. To be specific: In November 2009, participants 2, 4, 5, 6, 7, 9, 10, 11, 13, 16, and 17 stated that they would prefer to raise rates more rapidly than in the staff outlook. Participants 2, 6, 7, 10, 11, and 13 have stronger inflation forecasts than do the staff. Participants 7 and 9 have long-term inflation goals of 1.5 percent, not 2 percent. Participant 17 has a stronger growth forecast than does the staff. Participants 5 and 16 favor the use of a different rule for monetary policy, in the sense that they would like to raise rates to head off potential financial imbalances. In November 2010, participants 1, 7, 10, 12, 14, and 15 stated that they would either prefer to raise rates more rapidly or undertake a smaller amount of asset purchases than in the staff outlook. All of them had a long-run inflation target below 2 percent.

16. Here, I assume (as is true in new Keynesian models and the Federal Reserve's FRBUS model) that the FOMC's current interest rate choices have some effect on current outcomes. In contrast, Svensson's (1997) annual model assumes that current monetary policy choices have an impact on output in one year and an impact on inflation in two years. 
which can be written as an interest rate rule:

$$
i=i^{*}+\beta \lambda^{-1}\left(\pi-\pi^{*}\right) .
$$

The slope in this last relationship converges to infinity as the weight in the objective on interest rate gaps converges to zero. Basically, an interest rate rule like the Taylor rule calls for the Federal Reserve to trade off its pursuit of mandated goals against the objective of keeping the level of accommodation close to its long-run average.

\section{I.D. The Taylor Rule and the Forward Guidance Deficit}

As of November 2009, the FOMC had already lowered the target range for the federal funds rate to near zero and had bought a large quantity of longterm assets. What else could the committee have possibly done to stimulate inflation and employment? In this subsection, I argue that the FOMC staff's analysis at the time suggested that the committee could have facilitated a faster economic recovery by using forward guidance that clearly indicated its intention to be much more patient in its removal of accommodation than was implied by the Taylor rule.

During the period from November 2009 to November 2010, the FOMC provided a qualitative form of forward guidance, saying that it anticipated that the federal funds rate would remain extraordinarily low for "an extended period." As Vice Chairman William Dudley noted, this phrase was widely understood as meaning that "no tightening was likely for more than six months" (FOMC 2009b, p. 168)..$^{17}$ The committee was concerned throughout this period that this forward guidance would be regarded as a commitment, while it was only meant as a forecast. ${ }^{18}$

In November 2010, the FOMC staff presented a policy option whereby the committee would adopt a stronger form of forward guidance. According to this guidance, the committee would state that it intended to keep the federal funds rate extraordinarily low, at least until mid-2012. The proposed guidance came with a number of escape clauses, designed to prepare the public for the possibility that the FOMC might raise the federal funds rate more rapidly. Only two committee participants spoke in favor of

17. See also the results of the primary dealer survey reported in FOMC (2009a, p. 5).

18. See, for example, Chairman Bernanke's remarks in FOMC (2010b, p. 119): "This is clearly not a fixed time commitment. It is a conditional statement. . . I would just ask . . . that everybody emphasize in talking about this publicly that it is conditional and that we are tying our policy to the state of the economy." 
this change in forward guidance. ${ }^{19}$ In the end, the committee followed the lead of Chairman Ben Bernanke and Governor Janet Yellen, who felt that including this language in the statement would add little accommodation, given the then-current market expectations of the initial date of liftoff.

Actually, the FOMC staff's analysis at the two November meetings supported the adoption of much more aggressive forms of forward guidance than the mid-2012 date. The staff routinely provided forecasts of the optimal path of federal funds rate target choices that were based on the benchmark FRB-US model. ${ }^{20}$ In both November 2009 and November 2010, these optimal control exercises resulted in interest rate paths that stayed at 0.25 percent until the unemployment rate fell to about 5 percent. ${ }^{21}$ This delay in the initiation of interest rate increases provides considerably more monetary accommodation than results from following the recommendations of the Taylor rule.

Interestingly, these 2009-10 optimal control prescriptions are both relatively close to what the FOMC actually ended up doing: It did not raise the federal funds rate target range from its 2008 level until the unemployment rate was 5 percent. But the policy is much more stimulative in the model because people know well in advance that the Federal Reserve intends to keep interest rates low until the unemployment rate hits 5 percent. They certainly did not have that knowledge in the early days of the recovery. In late 2009, Blue Chip forecasters expected the FOMC to first raise interest rates when the unemployment rate was near 10 percent (Bernanke 2012, note 25 ).

More than two years later, in December 2012, the FOMC implemented a new kind of forward guidance that committed to keeping the federal funds rate extraordinarily low-at least as long as the unemployment rate stayed above a particular numerical threshold (and as long as inflation and inflation expectations stayed under control). The FOMC staff's analysis

19. In an earlier draft, I mistakenly wrote that there was no support. That mistake is somewhat ironic, because along with Sandra Pianalto, then president of the Federal Reserve Bank of Cleveland, I was actually one of the two participants who spoke in favor of adding this language to the statement. See pages 149-50 and 167 of FOMC (2010c).

20. The term "optimal" refers to minimizing a loss function that puts equal weight on squared deviations of inflation from 2 percent, squared deviations of the unemployment rate from the natural rate, and squared interest rate changes. The last term is motivated by the staff's desire to capture the FOMC's apparent aversion to interest rate changes. See Svensson and Tetlow (2005) for an extensive analysis of the optimal policy projections made by the FOMC staff.

21. This is a description of the relevant graphs on page 25 of Federal Reserve Board staff (2009b) and page 3 of Federal Reserve Board staff (2010b). 
available at its November 2009 and 2010 meetings suggests that its forecasts for both unemployment and inflation would have been considerably more optimistic if the FOMC had chosen to implement an aggressive form of threshold-based forward guidance at either of those meetings.

More specifically, suppose the FOMC had announced sometime in 2010 that its intention was to keep the federal funds rate extraordinarily low, at least until the unemployment rate reached 5 percent (as long as inflation and inflation expectations stayed under control). According to the staff's optimal control exercises in late 2009 and late 2010, this aggressive forward guidance would have brought the unemployment rate back to precrisis levels about one year earlier than under the staff's benchmark outlook, while the inflation rate would have returned to target within the forecast horizon. ${ }^{22}$

So why did the FOMC not adopt these stronger forms of forward guidance? There is little by way of an explicit answer in the available transcripts. We shall see below that participants expressed significant concerns about the costs associated with asset purchases. But there are no similar mentions of costs associated with aggressive forward guidance. It seems, instead, that specific and strong forms of forward guidance were viewed as simply being too far outside the box in 2009 and 2010. The box centered on (if was not defined by) the staff's benchmark outlook for the committee's future choices for the federal funds rate target. And, as I discussed above, this benchmark outlook was based on the presumption that the committee would follow the Taylor rule (Federal Reserve Board staff 2010a, p. 30).

\section{I.E. Asset Purchases}

The FOMC relied heavily on long-term asset purchases as a form of monetary stimulus during the recovery. Its staff regularly presented possible options to the committee that featured more aggressive use of this tool. For example, in November 2009, the staff presented a policy option

22. To the extent that one views asset purchases as being stimulative, this forecast underestimates what the FOMC could have expected to achieve using its tools. And there is another, subtler, reason why the forecast underestimates what the FOMC could achieve in terms of unemployment and inflation. In the optimal control exercise, the staff uses a loss function that puts substantial weight on interest rate changes. That loss function leads the FOMC to begin to raise rates too early and too slowly, relative to the optimal path under a loss function that does not put any weight on interest rate changes. Like the staff's baseline FRB-US model, this comparison abstracts from the possibility that a faster recovery would have had permanent positive effects on the long-run level of economic activity. Chairman Bernanke discusses this benefit of additional stimulus in some detail in FOMC (2010c, p. 99). 
to the FOMC according to which the committee would have lengthened the duration of an ongoing asset purchase program. The staff argued that doing so would allow the FOMC to accelerate the economy's return to full employment, guard against downside risks, and raise unduly low inflation. But no participant spoke in support of this policy option. ${ }^{23}$

After its November 2010 meeting, the FOMC announced that it would purchase $\$ 600$ billion in long-term assets, in a policy action that became known as QE2 (referring to a second round of quantitative easing). However, within the meeting, its staff presented a policy option whereby the committee would have bought $\$ 1$ trillion in long-term assets. ${ }^{24}$ Again, the staff argued that this step would enable the committee to accelerate the pace of the recovery in both inflation and employment. But no participant openly supported this policy option (and only one, participant 8, endorsed it in his or her SEP submission). ${ }^{25}$

There were a number of reasons behind the FOMC's reluctance to undertake a larger asset purchase program. In a nonroutine October 2010 committee meeting about potential forms of additional accommodation,

23. From the October 2009 Bluebook: "The committee may view the staff's economic outlook, with its very protracted return to full employment, as producing unacceptably poor outcomes given the committee's dual mandate. Or participants might believe there remains a nonnegligible risk that the economy could suffer a relapse and fall back into recession next year when some of the lending facilities and other government programs wind down. Policymakers may also be troubled by continued inflation readings well below the inflation objectives implicit in the majority of their longer-run projections. For these reasons, they may judge that additional monetary stimulus would be appropriate. The committee might conclude that an effective way to provide such stimulus would be to expand the amount of agency MBS [mortgage-backed securities] purchases and to extend the time frame for conducting agency MBS and agency debt transactions (thereby allowing a higher amount of agency debt to be bought without causing market disruption)" (Federal Reserve Board staff 2009b, p. 41).

24. From the October 2010 Tealbook: "Policymakers may believe that without fairly aggressive policy action soon, both employment and inflation will likely be below the committee's objectives for these variables for a very substantial period. Moreover, they may be worried that very low inflation poses significant risks to the recovery. If so, the committee may wish to provide more substantial policy accommodation at this meeting, as in Alternative A [which involved purchasing $\$ 1$ trillion of long-term assets, rather than $\$ 600$ billion]. Committee members may, like the staff, expect the economic recovery to remain quite gradual, even with the additional $\$ 600$ billion expansion of the Federal Reserve's balance sheet envisioned in Alternative B. In the staff's baseline projection, the unemployment rate does not fall below 9 percent until 2012, and inflation remains below levels that the committee sees as consistent with its objectives for much longer. Members may see such outcomes as unacceptable" (Federal Reserve Board staff 2010b, p. 18).

25. The staff presented another option, under which the committee would not undertake any new asset purchases. A couple of participants spoke in favor of this option. 
I pointed out that the theoretical literature offered little support for the use of asset purchases as way to provide accommodation (FOMC 2010a, pp. 19-22). I also suggested five immediate risks associated with the use of asset purchases: ${ }^{26}$

- There was likely to be huge market uncertainty about the eventual stock of our purchases (which, according to the FOMC, was what mattered for the stimulus).

- Other large holders of long-term Treasury bonds could offset the FOMC's policy action by markedly reducing their positions.

- There could be an untoward response in the value of the dollar relative to other currencies.

-If the Federal Reserve's balance sheet ever grew to be $\$ 3$ trillion to $\$ 4$ trillion in size, the FOMC might not have the tools necessary to raise rates when desired.

- The Federal Reserve would be taking duration risk onto the balance sheet of taxpayers, who might not be too pleased about this action.

I would say that, six years later, the risks that I mentioned have largely proven to be manageable or insubstantial. (The last issue seems still up in the air.) But I would still argue that, as of late 2010, the downsides of asset purchases seemed large when the baseline economic theory suggested that their upside was near zero. ${ }^{27}$

In the discussion of risks above, I did not describe any financial stability concerns about the use of asset purchases (or forward guidance). It is important to keep in mind that I am discussing a period when the unemployment

26. I focus on my own remarks for what should be obvious reasons. I was certainly not the only participant at the meeting to express concerns about the downside risks associated with asset purchases. At an earlier meeting, in December 2009, Chairman Bernanke expressed his concern that additional asset purchases could destabilize inflation expectations or lead to undesirably sharp upward movements in commodity prices (FOMC 2009a, p. 135). Arguably, the latter actually did come to pass in the first half of 2011 after the FOMC launched QE2.

27. The baseline economic theory that I have in mind is that of Eggertsson and Woodford (2003), which builds on the work of Wallace (1981). In these papers, through a Ricardian equivalence argument, long-term asset purchases have no impact on long-term yields. There is much empirical work based on central bank asset purchase programs (both here and elsewhere) that suggests that, in fact, the purchases did lead to a decline in long-term yields. As Woodford (2012) points out, it is a distinct question whether this decline in long-term yields was associated with an increase in economic activity. I would guardedly endorse Bernanke's (2012) conclusion that, "Overall, however, a balanced reading of the evidence supports the conclusion that central bank securities purchases have provided meaningful support to the economic recovery while mitigating deflationary risks." 
rate was generally well above 9 percent. It was hard to see any signs of "overheating" or "froth" in financial markets. Much of the FOMC's discussion was about the magnitude of the downward pressures on inflation generated by economic slack. ${ }^{28}$ The situation was quite different in, say, mid-2013, when the FOMC began to publicly discuss its plans for tapering asset purchases. ${ }^{29}$

\section{I.F. The Risk of Ineffectiveness: Applying the Brainard Principle}

Many observers in the 2009-10 period, including several FOMC participants, suggested that there was a material risk that monetary policy would be less effective than during more normal economic times. To what extent does this kind of risk justify the FOMC's policy choices? We can address this question using the framework of Brainard (1967), who considered the problem of a policymaker who is choosing an action designed to keep the economy close to a target but is uncertain about the effects of the policy action. Brainard's analysis shows that it is optimal for that policymaker to only partially offset shocks to the economy. Why does the policymaker instead aim to offset a larger fraction of the shocks to the economy? Being more aggressive has little impact on the policymaker's performance if the policy action turns out to be ineffective. But being more aggressive will lead the policymaker to miss by a lot if the action turns out to be effective. This last consideration deters the policymaker from seeking to engage in a more complete offset.

Somewhat more formally, suppose the policymaker believes that inflation $\pi=\alpha a+\varepsilon$, where $a$ is the level of accommodation, and $(\alpha, \varepsilon)$ are independent random variables. Assume that the policymaker expects inflationary pressures to be unusually low, so that $E(\varepsilon)<\pi^{*}$. Assume, too, that policy effectiveness $\alpha$ equals $\alpha_{\text {NORM }}$ with probability $p$, and $\alpha_{L}$ with probability $(1-p)$, where $\alpha_{\text {NORM }}>\alpha_{L}>0$. The policymaker seeks to choose $a$ so as to minimize the expected squared deviation of inflation from its target $\pi^{*}$. The first-order condition for this problem is given by

$$
p \alpha_{\text {NORM }}\left(\alpha_{\text {NORM }} a+E(\varepsilon)-\pi^{*}\right)+(1-p) \alpha_{L}\left(\alpha_{L} a+E(\varepsilon)-\pi^{*}\right)=0,
$$

28. See FOMC (2009a) for a particularly thorough staff briefing along these lines.

29. Thomas M. Hoenig, then president of the Federal Reserve Bank of Kansas City, argued both publicly and privately in favor of tighter monetary policy in 2010 because of concerns about financial stability. See, for example, FOMC (2010a, p. 33). But he was largely alone on the FOMC in making those arguments at this time. 
which implies that

$$
E\left(\pi-\pi^{*}\right)=p\left(\alpha_{\text {NORM }} a+E(\varepsilon)-\pi^{*}\right)+(1-p)\left(\alpha_{L} a+E(\varepsilon)-\pi^{*}\right)<0 .
$$

Was this kind of uncertainty responsible for FOMC policymakers aiming for a modest recovery? To me, the evidence in the transcripts from 2009 and 2010 suggests not. ${ }^{30}$ Several FOMC principals did express concern that monetary policy might not be all that effective relative to historical norms (and I said as much above, where I discussed asset purchases). In light of this risk, Brainard's results imply that it would have been appropriate for the FOMC to undershoot its inflation and employment objectives. However, Brainard's analysis also implies that the risk of policy ineffectiveness should have led committee members to favor unusually high levels of accommodation - just not high enough to hit inflation and employment targets. Thus, in the above example, the choice of accommodation is equal to

$$
a=\frac{\left(p \alpha_{\text {NORM }}+(1-p) \alpha_{L}\right)\left(\pi^{*}-E(\varepsilon)\right)}{p \alpha_{\text {NORM }}^{2}+(1-p) \alpha_{L}^{2}}>\frac{\pi^{*}-E(\varepsilon)}{\alpha_{\text {NORM }}},
$$

which is the desired level when $p=1$. But as we have seen, the committee was loath during this period to adopt a more accommodative stance than the historically based prescriptions of the Taylor rule.

\section{I.G. An Analogy: The Federal Reserve's Great Depression Policy Error}

In this subsection, I briefly recapitulate Brunner and Meltzer's classic (1968) analysis of the Federal Reserve's policy error during the early part of the Great Depression. My basic point is that, just as in the 2009-10 period, the Federal Reserve's decisionmaking in the 1929-30 period was overly influenced by its predownturn decision framework. (To be clear, the policy error in 1929-30 led to a macroeconomic catastrophe, relative to what happened in 2009-10 and thereafter.)

Brunner and Meltzer argue that, during the 1920s, the Federal Reserve developed a framework to guide its decisionmaking about monetary policy that was sketched in the Board of Governors' 10th annual report (for 1923). A core element of this framework is the presumption that banks only borrowed reserves from the Federal Reserve when they needed those reserves to meet large deposit outflows. This presumption allowed policymakers to

30. See Williams (2013) for a countervailing perspective. 
use borrowed reserves as a signal about the relative tightness of monetary policy. Large quantities of borrowed reserves, especially if interest rates were high, signaled that money demand was high relative to supply, and the stance of policy was tight. Small quantities of borrowed reserves, especially if interest rates were low, signaled that money demand was low relative to supply, and the stance of policy was easy. In his magisterial history of the Federal Reserve, Meltzer (2003, p. 164) summarizes this framework as saying, "If borrowing and interest rates were low, policy was easy; if the two were high, policy was tight." Brunner and Meltzer refer to this framework as the Riefler-Burgess doctrine, in honor of Winfield Riefler and W. Randolph Burgess, two Federal Reserve staff economists who played a key role in its development. ${ }^{31}$

Brunner and Meltzer argue that the Federal Reserve's decisionmakers turned to the Riefler-Burgess doctrine during the early part of the Depression to help guide their thinking about monetary policy. For example, toward the end of 1930, member bank borrowing from the Federal Reserve was low relative to historical norms, even though interest rates were also unusually low. These metrics led many reserve bank leaders to conclude that monetary policy was easy—so easy that, in September 1930, the Federal Reserve strongly considered selling securities as a way to tighten monetary policy during a period of rampant deflation.

Meltzer (2003, p. 400) summarizes the Federal Reserve's thinking in the 1929-30 period as follows:

People see most clearly what they are trained or disposed to see. The RieflerBurgess ... doctrine was not a mechanical formula directing Federal Reserve policy, but it directed attention to member bank borrowing and market interest rates as measures of tightness and ease. In 1929-30, most members of the Federal Reserve Board and governors of the reserve banks accepted this framework. They believed that they had acted decisively to ease credit conditions, and on their measures they had.

This description, with the obvious substitutions, seems apt for the 2009-10 period as well.

\section{I.H. Summary}

In 2009 and 2010, the FOMC's desired recovery path for inflation and unemployment was close to its staff's benchmark outlook for these variables.

31. Meltzer (2003, p. 161) notes that Benjamin Strong, the first governor of the Federal Reserve Bank of New York, also contributed to the development of the Riefler-Burgess framework. 
In essence, the FOMC was targeting the staff forecast, which was based on the presumption that the committee would use the Taylor rule to make its interest rate choices. The resulting reliance on the Taylor rule led the committee to aim for a slow recovery in both inflation and unemployment.

Staff analysis in November 2009 and 2010 made clear to the FOMC that it did have ways available to provide additional stimulus to the economy. ${ }^{32}$ Yet these stimulative steps received little support within the FOMC. In terms of asset purchases, one can trace much of the FOMC's hesitancy to the risks of the tool itself. However, in terms of forward guidance, the FOMC's reluctance seems in no little part due to its unwillingness to commit to a pronounced deviation from its staff's benchmark outlook for the federal funds rate path. I believe that Chairman Bernanke summarized the sentiments of almost all FOMC meeting participants when he said, at the December 2009 meeting, "It's good for confidence and good for predictability for us to begin to normalize policy, to begin to operate in a way that people are more familiar with" (emphasis added) (FOMC 2009a, p. 136).

The FOMC seems likely to be just as guarded in its responses to future downturns. Recently, Chair Janet Yellen (2016) described how she foresaw the committee responding to a future recessionary shock. This response again treated a slightly more aggressive version of the Taylor rule as being a key benchmark for FOMC policy choices. The result-according to model-based simulations in a recent paper by David Reifschneider (2016), and as depicted in Yellen's (2016) figure 2-is that the unemployment rate would be above desirable levels for four years and the inflation rate would be below target for more than a decade. The Federal Reserve should instead contemplate responding to future shocks using a discretionary framework of the kind described by Ali Alichi and others (2015).

\section{Modeling Rules versus Discretion}

In the preceding section, I described how the FOMC could have achieved its inflation and employment objectives more rapidly if it had been willing to deviate more from its precrisis reaction function, as proxied by the Taylor rule. Of course, the Taylor rule is only one possible rule. In this section, I describe a simple model that will allow for a more general comparison of central bank discretion with central bank rules.

32. There are many other steps that the Federal Reserve could have taken, including, for example, raising its inflation target. I have focused on the two tools that were recommended to the FOMC by its staff. 


\section{II.A. Environment}

Consider the following three-stage environment, in which the stages are indexed $0,1,2$. At the final stage, inflation $\pi$ is realized. It is the sum of four components:

$$
\pi=x_{R}+x_{N R}+a+\varepsilon .
$$

The first component $\left(x_{R}\right)$ is a signal that is revealed at the beginning of stage 1 that is rulable- that is, it can be encoded into a policy rule. ${ }^{33}$ The second component $\left(x_{N R}\right)$ is a signal that is observed (at least by the central bank and possibly by others) at the beginning of stage 1, but is nonrulable (cannot be written into a rule). The third component ( $a$ ) is the level of accommodation determined by the central bank at stage 1 . The final component $(\varepsilon)$ is a random shock to inflation that is realized at stage 2 .

It is common knowledge at stage 0 that $x_{R}$ has a continuous density of $g$ over its support $X_{R}$. For now, I assume that it is also common knowledge at stage 0 that, conditional on $x_{R},\left(x_{N R}, \varepsilon\right)$ are mutually independent mean-zero random variables with respective supports $X_{N R}$ and E. Their respective continuous densities, conditional on $x_{R}$, are represented by $f\left(\cdot \mid x_{R}\right)$ and $h\left(\cdot \mid x_{R}\right)$. I assume that $\left(X_{R}, X_{N R}, \mathrm{E}\right)$ are all intervals on the real line.

The objective function of the central bank is defined over inflation and is known to be

$$
-\left(\pi-\pi_{C B}\right)^{2}
$$

The objective function of society over inflation is known to be

$$
-\left(\pi-\pi_{s o c}\right)^{2}
$$

These objective functions allow for the possibility that the central bank's inflation target $\pi_{C B}$ is distinct from society's inflation target $\pi_{S O C}$.

\section{II.B. Interpretation of the Environment}

The environment has three main attributes. The first is that the central bank has information $x_{N R}$ available that is useful in forecasting inflation, but cannot be used as the basis for a policy rule. The idea behind $x_{N R}$ being

33. This component could include a host of "forward-looking" variables, like consumption or stock prices. 
nonrulable is that it is a complicated function of possibly many timevarying factors on inflation (thus, $x_{N R}=\theta^{\prime} \beta$, where $\theta$ and $\beta$ are both very long vectors). This emphasis on the importance of nonrulable information is consistent with the fact that most central banks base their inflation forecasts on objects like potential output and the natural rate of interest that are complex functions of observable and unobservable data (like staff judgments of various kinds). I view this modeling as being a simple way to formalize Svensson's (2003, p. 428) observation that "central banks have developed very elaborate and complex decisionmaking processes, where large amounts of information are collected, processed, and analyzed, and where considerable judgment is exercised."

The second attribute is that the central bank's objective for inflation could differ from society's. There are many possible reasons for this bias, such as various kinds of political economy effects. However, the central bank's horizon could simply be short-run, while society's is long-run. In this way, the model can capture the effects of time inconsistency. ${ }^{34}$

The final attribute of import is that society has no way to offer outcomecontingent rewards or punishments to the central banker. In elegant work, Carl E. Walsh (1995) showed how such rewards or punishments can be used to align a central banker's incentives with society's. However, it does seem challenging to implement such schemes in reality (at least in the United States).

\section{II.C. Delegation Games}

My results are about delegation games, in which the central bank can directly choose the level of accommodation from a set of possibilities. In this subsection, I show that any equilibrium outcome of any game played by the central bank in this environment is an equilibrium outcome of a delegation game.

I define a game to be a pair $(C, \alpha)$. Here, the first component $C$ is a correspondence from the set $X_{R}$ of realizations of the rulable signal into some set $\Gamma$ of actions for the central bank. The game component $\alpha$ is a continuous outcome function that maps $\left(\Gamma \times X_{R}\right)$ into the real line; given the rulable

34. To be a little more precise: This one-period model is meant to capture the central bank's decision problem after the private sector has made its decisions that feed into inflation within the current period. This timing means that the central bank's objective in this decision problem does not include the impact of its reaction function on the private sector's expectations - exactly the time consistency problem highlighted originally by Kydland and Prescott (1977). 
signal, it describes the accommodation resulting from the central bank's choice of $\gamma$. The set of equilibria $\operatorname{EQM}(C, \alpha)$ to the game $(C, \alpha)$ consists of all functions $\gamma^{*}: X_{R} \times X_{N R} \rightarrow \Gamma$ such that $\gamma^{*}$ is the central bank's best response as a function of the rulable and nonrulable signals $\left(x_{R}, x_{N R}\right)$ about inflation:

$$
\gamma^{*}\left(x_{R}, x_{N R}\right) \in \underset{\gamma \in C\left(x_{R}\right)}{\operatorname{argmax}}\left(-\int_{\varepsilon \in \mathrm{E}}\left(\alpha\left(\gamma, x_{R}\right)+x_{R}+x_{N R}+\varepsilon-\pi_{S O C}\right)^{2} h\left(\varepsilon \mid x_{R}\right) d \varepsilon\right) .
$$

I define delegation game to be a game $(C, \alpha)$ in which the range $\Gamma$ of the correspondence $C$ is a subset of the real line and the outcome function $\alpha\left(\gamma, x_{R}\right)=\gamma$. In a delegation game, the central bank directly chooses an accommodation level from a set of possibilities that can vary with the rulable information $x_{R}$.

The following proposition shows that there is no loss in generality in restricting attention to the equilibrium outcomes of delegation games.

Proposition 1. Consider a game $(C, \alpha)$ in which $\gamma^{*} \in \operatorname{EQM}(C, \alpha)$. Then, let $\Gamma^{\prime}=\bigcup_{x_{R} \in X_{R}} \bigcup_{x_{N R} \in X_{N R}} \alpha\left(\gamma^{*}\left(x_{R}, x_{N R}\right), x_{R}\right)$. Define the delegation game $\left(C^{\prime}, \alpha^{\prime}\right)$ by

$$
\begin{aligned}
C^{\prime}\left(x_{R}\right) & =\bigcup_{x_{N R}^{\prime} \in X_{N R}} \alpha\left(\gamma^{*}\left(x_{R}, x_{N R}^{\prime}\right), x_{R}\right), \\
\alpha^{\prime}\left(\gamma, x_{R}\right) & =\gamma .
\end{aligned}
$$

Then $\gamma^{\prime}$ is an equilibrium to $\left(C^{\prime}, a^{\prime}\right)$, where

$$
\gamma^{\prime}\left(x_{R}, x_{N R}\right)=\alpha\left(\gamma^{*}\left(x_{R}, x_{N R}\right), x_{R}\right) \forall\left(x_{R}, x_{N R}\right) \in\left(X_{R} \times X_{N R}\right) .
$$

Proof. For any $x_{R} \in X_{R}$ and any $x_{N R} \in X_{N R}$, we know that $\gamma^{*}\left(x_{R}, x_{N R}\right) \in C\left(x_{R}\right)$. If the central bank observes rulable information $x_{R}$ and nonrulable information $x_{N R}$, then the central bank weakly prefers the action $\gamma^{*}\left(x_{R}, x_{N R}\right)$ to the action $\gamma^{*}\left(x_{R}, x_{N R}^{\prime}\right)$ for any $x_{N R}^{\prime}$, so that for any $\left(x_{R}, x_{N R}, x_{N R}^{\prime}\right)$,

$$
\begin{aligned}
& -\int_{\varepsilon \in \mathrm{E}}\left(x_{R}+x_{N R}+\varepsilon+\alpha\left(\gamma^{*}\left(x_{R}, x_{N R}\right), x_{R}\right)-\pi_{S O C}\right)^{2} h\left(\varepsilon \mid x_{R}\right) d \varepsilon \\
\geq & -\int_{\varepsilon \in \mathrm{E}}\left(x_{R}+x_{N R}+\varepsilon+\alpha\left(\gamma^{*}\left(x_{R}, x_{N R}^{\prime}\right), x_{R}\right)-\pi_{S O C}\right)^{2} h\left(\varepsilon \mid x_{R}\right) d \varepsilon .
\end{aligned}
$$

This implies that for any $\left(x_{R}, x_{N R}, x_{N R}^{\prime}\right)$,

$$
\begin{aligned}
& -\int_{\varepsilon \in \mathrm{E}}\left(x_{R}+x_{N R}+\varepsilon+\alpha^{\prime}\left(\gamma^{\prime}\left(x_{R}, x_{N R}\right), x_{R}\right)-\pi_{S O C}\right)^{2} h\left(\varepsilon \mid x_{R}\right) d \varepsilon \\
\geq & -\int_{\varepsilon \in \mathrm{E}}\left(x_{R}+x_{N R}+\varepsilon+\alpha^{\prime}\left(\gamma^{\prime}\left(x_{R}, x_{N R}^{\prime}\right), x_{R}\right)-\pi_{S O C}\right)^{2} h\left(\varepsilon \mid x_{R}\right) d \varepsilon .
\end{aligned}
$$


Equivalently:

$$
\begin{aligned}
& -\int_{\varepsilon \in \mathrm{E}}\left(x_{R}+x_{N R}+\varepsilon+\alpha^{\prime}\left(\gamma^{\prime}\left(x_{R}, x_{N R}\right), x_{R}\right)-\pi_{S O C}\right)^{2} h\left(\varepsilon \mid x_{R}\right) d \varepsilon \\
& =\max _{\gamma \in C^{\prime}\left(x_{R}\right)}\left(-\int_{\varepsilon \in \mathrm{E}}\left(x_{R}+x_{N R}+\varepsilon+\alpha^{\prime}\left(\gamma, x_{R}\right)-\pi_{S O C}\right)^{2} h\left(\varepsilon \mid x_{R}\right) d \varepsilon\right) .
\end{aligned}
$$

This proves the proposition's claim that $\gamma^{\prime}$ is an equilibrium to the delegation game $\left(C^{\prime}, \alpha^{\prime}\right)$.

Proposition 1 is, essentially, an application of the revelation principle in this setting. In keeping with proposition 1, I focus on delegation games in the remainder of the paper. I pose the rules-versus-discretion question as being about the nature of the restrictions embedded in the correspondence $C$.

\section{II.D. Kinds of Delegation Games}

In light of proposition 1, we can restrict attention to delegation games. There are three possible kinds of delegation games. The first kind are rules that restrict the central bank's choice to depend only on the rulable information $x_{R}$ about future inflation.

Definition 1. Suppose $(C, \alpha)$ is a delegation game. The game is said to be a rule if $C\left(x_{R}\right)$ is a singleton for almost all $x_{R} \in X_{R}$.

In a rule, the public knows exactly what the central bank will do as a function of the rulable variable $x_{R}$.

The second kind of delegation game features discretion, in the sense that the central bank is always allowed to choose any level of accommodation.

Definition 2. Suppose $(C, \alpha)$ is a delegation game. The game is said to feature discretion if $C\left(x_{R}\right)$ is the entire real line for almost all $x_{R} \in X_{R}$.

All other delegation games are said to feature constrained discretion.

Definition 3. Suppose $(C, \alpha)$ is a delegation game. The game is said to feature constrained discretion if, for some set of $x_{R} \in X_{R}$ that has positive measure, $C\left(x_{R}\right)$ is a proper subset of the real line and if, for some set of $x_{R}^{\prime} \in X_{R}$ with positive measure, $C\left(x_{R}^{\prime}\right)$ is not a singleton.

I am largely interested in comparing outcomes under rules with outcomes under games that feature discretion. The following results help with this investigation. Define the stage 0 social welfare associated with any rule $(C, \alpha)$ to be the expected value of the social planner's objective implied by that rule:

$$
\begin{gathered}
-\int_{x_{R} \in X_{R}} \int_{x_{N R} \in X_{N R}} \int_{\varepsilon \in \mathrm{E}}\left(x_{R}+x_{N R}+C\left(x_{R}\right)+\varepsilon-\pi_{S O C}\right)^{2} \\
h\left(\varepsilon \mid x_{R}\right) f\left(x_{N R} \mid x_{R}\right) g\left(x_{R}\right) d \varepsilon d x_{N R} d x_{R} .
\end{gathered}
$$


Proposition 2. Consider the rule $\left(C^{*}, \alpha\right)$ such that $C^{*}\left(x_{R}\right)=\pi_{S O C}-x_{R}$ for any $x_{R} \in X_{R}$. No other rule has higher stage 0 welfare.

Proof. Rewrite the stage 0 welfare associated with the rule $(C, \alpha)$ as:

$$
\begin{gathered}
-\int_{x_{R} \in X_{R}} \int_{x_{N R} \in X_{N R}} \int_{\varepsilon \in \mathrm{E}}\left[\left(x_{R}+C\left(x_{R}\right)-\pi_{S O C}\right)^{2}+\left(x_{N R}+\varepsilon\right)^{2}\right] \\
h\left(\varepsilon \mid x_{R}\right) f\left(x_{N R} \mid x_{R}\right) g\left(x_{R}\right) d \varepsilon d x_{N R} d x_{R} \\
-2 \int_{x_{R} \in X_{R}} \int_{x_{x_{N} \in X_{N R}}} \int_{\varepsilon \in \mathrm{E}}\left(x_{R}+C\left(x_{R}\right)-\pi_{S O C}\right)\left(x_{N R}+\varepsilon\right) \\
h\left(\varepsilon \mid x_{R}\right) f\left(x_{N R} \mid x_{R}\right) g\left(x_{R}\right) d \varepsilon d x_{N R} d x_{R} .
\end{gathered}
$$

Recall that

$$
\int_{x_{N R} \in X_{N R}} \int_{\varepsilon \in \mathrm{E}}\left(x_{N R}+\varepsilon\right) h\left(\varepsilon \mid x_{R}\right) f\left(x_{N R} \mid x_{R}\right) d \varepsilon d x_{N R}=0 \forall x_{R} \in X_{R} .
$$

Hence, the stage 0 welfare can be expressed as

$$
\begin{gathered}
-\int_{x_{R} \in X_{R}}\left(x_{R}+C\left(x_{R}\right)-\pi_{S O C}\right)^{2} g\left(x_{R}\right) d x_{R} \\
-\int_{x_{R} \in X_{R}} \int_{x_{N R} \in X_{N R}} \int_{\varepsilon \in \mathrm{E}}\left(x_{N R}+\varepsilon\right)^{2} h\left(\varepsilon \mid x_{R}\right) f\left(x_{N R} \mid x_{R}\right) g\left(x_{R}\right) d \varepsilon d x_{N R} d x_{R},
\end{gathered}
$$

and this expression is maximized by setting the integrand to zero- - that is, setting $C\left(x_{R}\right)=\pi_{S O C}-x_{R}$.

The best rule is to offset the inflationary pressures embedded in the rulable signal $x_{R}$. This rule provides stage 0 social welfare equal to

$$
\begin{aligned}
V_{r u l e}^{o p t}= & -\int_{x_{R} \in X_{R}} \int_{x_{N R} \in X_{N R}} \int_{\varepsilon \in \mathrm{E}}\left(x_{N R}+\varepsilon\right)^{2} h\left(\varepsilon \mid x_{R}\right) f\left(x_{N R} \mid x_{R}\right) g\left(x_{R}\right) d \varepsilon d x_{N R} d x_{R} \\
= & -\int_{x_{R} \in X_{R}} \int_{x_{N R} \in X_{N R}} x_{N R}^{2} f\left(x_{N R} \mid x_{R}\right) g\left(x_{N R}\right) d x_{N R} d x_{R} \\
& -\int_{x_{R} \in X_{R}} \int_{\varepsilon \in \mathrm{E}} \varepsilon^{2} h\left(\varepsilon \mid x_{R}\right) g\left(x_{R}\right) d \varepsilon d x_{R}=-\operatorname{Var}\left(x_{N R}\right)-\operatorname{Var}(\varepsilon) .
\end{aligned}
$$

Here, I use the notation $\operatorname{Var}(\cdot)$ to refer to the variance of the relevant random variable, as of stage 0 . The stage 0 social welfare is the negative of the sum of two components: the variance of the nonrulable inflation shock $x_{N R}$, and the variance of the ex post inflationary shock $\varepsilon$. 


\section{Main Theoretical Results}

We can now use the theoretical model described in the preceding section to assess whether rules are superior to discretion, or vice versa. The answers to this question generally trade off two quantities: the magnitude of central bank bias versus the variance reduction gains associated with allowing the central bank to offset shocks to inflation that are hard to encode in rules.

Suppose, first, that there is no nonrulable information and no inflation bias. Then discretion is equivalent to the best possible rule.

Proposition 3. Suppose $X_{N R}=\{0\}$, so that there is no nonrulable information, and $\pi_{C B}=\pi_{S O C}$, so that the central bank is unbiased. There is a unique equilibrium outcome to any delegation game with discretion, and its stage 0 social welfare is equal to the stage 0 social welfare implied by the best possible rule.

Proof. Consider any delegation game $(C, \alpha)$. Then, at stage 1 , the central bank solves the problem

$$
\max _{a \in C\left(x_{R}\right)}\left(-\int_{\varepsilon \in \mathrm{E}}\left(x_{R}+\varepsilon+a-\pi_{S o C}\right)^{2} h\left(\varepsilon \mid x_{R}\right) d \varepsilon\right),
$$

which can be rewritten as

$$
\max _{a \in C\left(x_{R}\right)}\left(-\int_{\varepsilon \in \mathrm{E}} \varepsilon^{2} h\left(\varepsilon \mid x_{R}\right) d \varepsilon-\left(x_{R}+a-\pi_{S O C}\right)^{2}\right) .
$$

Suppose the delegation game features discretion, so that $C\left(x_{R}\right)$ is the entire real line. Then the unique solution to this problem would be to set

$$
a=\pi_{S O C}-x_{R} .
$$

The stage 0 welfare associated with this equilibrium is easily seen to be $V_{\text {rule }}^{\text {opt }}$.

The proposition demonstrates that, without any nonrulable information or bias, the best rule is equivalent to discretion.

At this point, it is worth noting something obvious that is often ignored. Many economists will airily say that "rules are better than discretion." The proposition given above clearly shows how sloppy this language is. In the context without bias or nonrulable information, any rule other than the best one provides less stage 0 welfare. Hence, it is not true that rules are as good as discretion. What is true is that exactly one carefully chosen rule does as well as discretion. 
Suppose, next, that the central bank's information about inflation is all rulable and that the central bank is biased. Then discretion is worse, in terms of stage 0 welfare, than the best possible rule.

Proposition 4. Suppose $X_{N R}=\{0\}$, so that all available information about inflation is rulable, and $\pi_{C B} \neq \pi_{S O C}$, so that the central bank has an inflation bias. There is a unique equilibrium outcome to any delegation game that features discretion and its stage 0 social welfare is less than $V_{r u l e}^{\text {opt }}$ (the social welfare implied by the best possible rule).

Proof. Consider any delegation game $(C, \alpha)$. Then, in stage 1 , the central bank solves the problem

$$
\max _{a \in C\left(x_{R}\right)}\left(-\int_{\varepsilon \in \mathrm{E}}\left(x_{R}+\varepsilon+a-\pi_{C B}\right)^{2} h\left(\varepsilon \mid x_{R}\right) d \varepsilon\right),
$$

which can be rewritten as

$$
\max _{a \in C\left(x_{R}\right)}\left(-\int_{\varepsilon \in \mathrm{E}} \varepsilon^{2} h\left(\varepsilon \mid x_{R}\right) d \varepsilon-\left(x_{R}+a-\pi_{C B}\right)^{2}\right) .
$$

Suppose the delegation game features discretion. Then the unique solution to the central bank's stage 1 problem is

$$
a=\pi_{C B}-x_{R} .
$$

The stage 0 welfare associated with this equilibrium outcome is given by

$$
-\int_{x_{R} \in X_{R}} \int_{\varepsilon \in \mathrm{E}} \varepsilon^{2} h\left(\varepsilon \mid x_{R}\right) g\left(x_{R}\right) d \varepsilon d x_{R}-\left(\pi_{C B}-\pi_{S O C}\right)^{2},
$$

which equals

$$
V_{\text {rule }}^{\text {opt }}-\left(\pi_{C B}-\pi_{S O C}\right)^{2}
$$

In the case in which all information is rulable and the central bank is biased, discretion is strictly worse than the best rule. The sign of the bias does not matter for this result.

The case considered in proposition 4 is the one that most macroeconomists have in their minds when they think about the issue of rules versus discretion. The central bank is biased in its decisionmaking (because of time consistency and political economy considerations). Because of this bias, it is best to constrain the central bank with a rule.

However, in this paper I explicitly allow for the possibility that the central bank has information about inflation that cannot be written into a rule. 
As I explained above, the problem with discretion is that the central bank will systematically aim to generate suboptimal inflation. But there is a benefit to discretion: The central bank can use this flexibility to offset the impact of inflationary pressures that cannot be encoded into a rule. Intuitively, if the bias is sufficiently small, then the benefit of discretion outweighs the relevant cost. The following proposition provides the precise way to do the comparison when the relevant objectives are quadratic.

Proposition 5. Suppose

$$
\operatorname{Var}\left(x_{N R}\right)>\left(\pi_{C B}-\pi_{S O C}\right)^{2} .
$$

Then the unique equilibrium outcome implied by a delegation game with discretion has higher stage 0 welfare than the best rule.

Proof. Consider a delegation game with discretion. In stage 1, the central bank observes $\left(x_{R}, x_{N R}\right)$ and then solves the problem

$$
\max _{a \in \mathbb{R}}\left(-\int_{\varepsilon \in \mathrm{E}}\left(x_{R}+x_{N R}+a+\varepsilon-\pi_{C B}\right)^{2} h\left(\varepsilon \mid x_{R}\right) d \varepsilon\right) .
$$

The maximand in this problem can be rewritten as

$$
-\int_{\varepsilon \in \mathrm{E}} \varepsilon^{2} h\left(\varepsilon \mid x_{R}\right) d \varepsilon-\int_{\varepsilon \in \mathrm{E}}\left(x_{R}+x_{N R}+a-\pi_{C B}\right)^{2} h\left(\varepsilon \mid x_{R}\right) d \varepsilon .
$$

The solution is to set $a=\pi_{C B}-x_{R}-x_{N R}$. The stage 0 social welfare associated with this equilibrium is given by

$$
-\int_{x_{R} \in X_{R}} \int_{\varepsilon \in \mathrm{E}} \varepsilon^{2} h\left(\varepsilon \mid x_{R}\right) g\left(x_{R}\right) d \varepsilon d x_{R}-\left(\pi_{S O C}-\pi_{C B}\right)^{2},
$$

which can be rewritten as

$$
V_{r u l e}^{o p t}+\int_{x_{R} \in X_{R}} \int_{x_{N R} \in X_{N R}} x_{N R}^{2} f\left(x_{N R} \mid x_{R}\right) g\left(x_{R}\right) d x_{N R} d x_{R}-\left(\pi_{S O C}-\pi_{C B}\right)^{2},
$$

which proves the proposition.

The next proposition shows that the reverse is true; in terms of stage 0 welfare, the best possible rule is better than discretion if the bias is sufficiently large in absolute value.

Proposition 6. Suppose

$$
\operatorname{Var}\left(x_{N R}\right)<\left(\pi_{C B}-\pi_{S O C}\right)^{2} .
$$


Then the unique equilibrium outcome implied by any delegation game that features discretion has lower stage 0 welfare than the best rule.

Proof. This proof is the same as that for proposition 5.

The proposition shows that, if the bias is sufficiently large relative to the nonrulable information available to the central bank about inflation, then the best possible rule is better than discretion. Again, I stress that the proposition only applies to the best possible rule (and to a set of rules in the neighborhood of the best possible rule). It does not apply to all possible rules.

The propositions given above all assume that, at stage 0 , society was able to form a prior distribution over possible realizations of the central bank's nonrulable information. However, given the nebulous nature of that information, it may well be more reasonable to assume that society wants to formulate a delegation game that is robust to extreme outcomes of the central bank's nonrulable information. To be more precise, suppose a game has an equilibrium outcome given by $a^{*}\left(x_{R}, x_{N R}\right)$. Then define the robust social welfare from this outcome to be

$$
\min _{x_{N N R} \in X_{N R}}\left(\begin{array}{c}
-\int_{x_{R} \in X_{R}}( \\
\left.x_{R}+x_{N R}+a^{*}\left(x_{R}, x_{N R}\right)-\pi_{S O C}\right)^{2} g\left(x_{R}\right) d x_{R} \\
-\int_{x_{R} \in X_{R}} \int_{\varepsilon \in \mathrm{E}} \varepsilon^{2} h\left(\varepsilon \mid x_{R}\right) g\left(x_{R}\right) d \varepsilon d x_{R}
\end{array}\right) .
$$

It is simple to show that, with respect to robust social welfare, discretion is better than any rule, as long as the largest possible nonrulable inflation shock is larger in absolute value than the central bank's inflation bias.

Proposition 7. Suppose $X_{N R}=[-M, M]$ and $\left|\pi_{C B}-\pi_{S O C}\right|<M$. Then the robust social welfare implied by any rule is less than the robust social welfare implied by the unique equilibrium outcome of a delegation game that features discretion.

Proof. In a delegation game with discretion, the unique equilibrium outcome is given by $a^{*}\left(x_{R}, x_{N R}\right)=\pi_{C B}-x_{R}-x_{N R}$. The robust social welfare is

$$
-\left(\pi_{S O C}-\pi_{C B}\right)^{2}-\int_{x_{R} \in X_{R}} \int_{\varepsilon \in E} \varepsilon^{2} h\left(\varepsilon \mid x_{R}\right) g\left(x_{R}\right) d \varepsilon d x_{R} .
$$

In a delegation game that is a rule, the robust social welfare is

$$
\min _{x_{N R} \in X_{N R}}\left(\begin{array}{c}
-\int_{x_{R} \in X_{R}}\left(x_{R}+x_{N R}+C\left(x_{R}\right)-\pi_{S O C}\right)^{2} g\left(x_{R}\right) d x_{R} \\
-\int_{x_{R} \in X_{R}} \int_{\varepsilon \in \mathrm{E}} \varepsilon^{2} h\left(\varepsilon \mid x_{R}\right) g\left(x_{R}\right) d \varepsilon d x_{R}
\end{array}\right) .
$$


The concavity of the objective function with respect to $x_{N R}$ means that this robust social welfare can be rewritten as

$$
\begin{gathered}
-\int_{x_{R} \in X_{R}} \int_{\varepsilon \in \mathrm{E}} \varepsilon^{2} h\left(\varepsilon \mid x_{R}\right) g\left(x_{R}\right) d \varepsilon d x_{R} \\
+\min _{x_{N R} \in\{-M, M\}}\left(-\int_{x_{R} \in X_{R}}\left(x_{R}+x_{N R}+C\left(x_{R}\right)-\pi_{S O C}\right)^{2} g\left(x_{R}\right) d x_{R}\right) .
\end{gathered}
$$

The second term can be rewritten as

$$
\begin{gathered}
-M^{2}-\int_{x_{R} \in X_{R}}\left(x_{R}+C\left(x_{R}\right)-\pi_{S O C}\right)^{2} g\left(x_{R}\right) d x_{R} \\
+\min _{x_{N R} \in\{-M, M\}}\left(-2 x_{N R} \int_{x_{R} \in X_{R}}\left(x_{R}+C\left(x_{R}\right)-\pi_{S O C}\right) g\left(x_{R}\right) d x_{R}\right) .
\end{gathered}
$$

The last term is nonpositive. Hence, the best rule is to set $C\left(x_{R}\right)=$ $\pi_{S O C}-x_{R}$, which gives rise to robust social welfare $-M^{2}$, which is less than the robust social welfare arising from discretion $-\left(\pi_{S O C}-\pi_{C B}\right)^{2}$. This proves the proposition.

As long as it is possible for nonrulable inflationary pressures to ever exceed the central bank's bias in absolute value, discretion is more robust than any rule.

It is easy to summarize the main theoretical findings. If the central bank's bias exceeds the standard deviation of the central bank's nonrulable information, then the best possible rule is better than discretion. If the central bank's bias is lower than the standard deviation of the central bank's nonrulable information, then all rules are worse than discretion. Perhaps most important, if the largest realization of the central bank's nonrulable information exceeds its bias in absolute value, then discretion is more robust than any rule.

\section{Discussion}

In this section, I discuss some aspects of the theoretical results derived above.

\section{IV.A. Inflationary Bias?}

The propositions in the previous section show that rules are dominated by discretion, as long as the central bank's inflationary bias is small in absolute value. In this subsection, I argue that the evidence suggests that the FOMC's 
inflation bias has been, at most, only modestly above zero during the past two decades. ${ }^{35}$

To make this argument, I need to first establish a benchmark for the socially optimal level of inflation. In many countries (such as Canada and the United Kingdom), elected governments have established what are intended to be long-term targets for inflation. Presumably, these targets can be seen as being relatively good proxies for socially optimal inflation. In the United States, no such target has been established. However, in early 2012, the FOMC formally established a long-term goal of keeping PCE inflation at 2 percent. ${ }^{36}$ Congress has, as of yet, made no attempt to modify this target. So here I treat the 2 percent target as being equivalent to the socially desirable level of inflation $\pi_{S O C}$.

We can gauge the FOMC's inflation bias in two different ways: in terms of the committee's inflation objectives, and in terms of actual outcomes. With respect to inflation objectives, at the last meeting of each year, the committee's staff provides inflation forecasts for the upcoming two years. These forecasts are conditioned on the staff's best projection of what the committee will actually do. Since 1997, the one- to two-year-ahead inflation forecasts have only rarely exceeded 2 percent and have never been as high as 2.25 percent. Hence, the staff did not see the FOMC as aiming for inflation well above 2 percent. Since 2007, the FOMC participants have submitted their own end-of-year inflation forecasts. As discussed above, these forecasts are conditioned on each participant's own assessment of appropriate monetary policy. The midpoint of the central tendency of the one- to two-year-ahead PCE inflation forecasts (constructed by discarding the three highest and three lowest forecasts) never exceeded 2 percent (even during periods of high unemployment) (Kocherlakota 2012).

Therefore, there is little evidence in the FOMC's projections of inflation that the committee is aiming for inflation to be materially above 2 percent. If we look at outcomes, we get a similar conclusion. During the past 20 years, the 60-month trailing average PCE inflation rate has never been above 3 percent. Even here, most of the upward misses with respect to inflation can be attributed to the surprisingly large run-up in oil prices in 2008. For the past 20 years, the 60-month trailing average core PCE inflation rate

35. The concerns about bias, both in the media and in academe, usually focus on the possibility that the FOMC has a positive inflation bias. So, I do not present evidence against the hypothesis that the FOMC's inflation bias was highly negative.

36. See FOMC (2016) for the most recent version of this statement. 
(which excludes goods and services related to food and energy) has never exceeded 2.25 percent.

Of course, inflation rose to unacceptably high levels during the 1970s. However, since that period, much has changed in FOMC practice. Perhaps most notably, both Chairman William Martin and Chairman Arthur Burns interacted relatively closely with the White House, compared to Chair Yellen or her immediate predecessors. The Federal Reserve is consequently much more independent of the short-term political pressures that often are argued to have been responsible for at least part of the Great Inflation (Meltzer 2013).

\section{IV.B. Communicating Challenges with Rules}

It is often argued that rules enhance the public's understanding of monetary policy. ${ }^{37}$ I use the theoretical framework given above to demonstrate that rules (or any form of constraint on discretion) make such communication more challenging. My basic point is that a discretionary central bank automatically reveals all its information about inflation. A rule-constrained central bank must seek other ways to reveal this information.

In a world with discretion, the central bank sets the level of accommodation, so that

$$
a^{*}\left(x_{R}, x_{N R}\right)=\pi_{C B}-x_{R}-x_{N R}
$$

The variable $x_{R}$ is known to the public, but the nonrulable information $x_{N R}$ may or may not be. The choice of accommodation, in and of itself, reveals $\left(\pi_{C B}-x_{N R}\right)$. If the central bank's bias is known (as I assume above), then the choice of accommodation reveals the nonrulable information $x_{N R}$.

In contrast, if the central bank is using a rule, the choice of accommodation reveals nothing about $x_{N R}$. It may well be true, however, that the central bank would like to reveal at least some of its private information about inflation, so as to reduce the private sector's uncertainty about inflation. The central bank would then need to supplement its choice of accommodation with separate communication about $x_{N R}$. In this sense, rules-or any constraints on central bank accommodation-serve to increase the central bank's communication challenge.

Thus, in this simple framework, discretion automatically reveals more information to the public than does a rule. Why, then, do observers often

37. See Taylor (2015, point 2), for example. Note that Taylor (2015) is based on Taylor (1998). 
argue that rules reduce uncertainty relative to discretion ${ }^{38}$ From an ex ante perspective, revealing more information at stage 1 does create more uncertainty at stage 0 . At stage 0 , the public knows that the central bank operating with discretion will reveal $\left(a^{*}, x_{R}, x_{N R}\right)$ at stage 1 . A central bank operating under a rule only reveals $\left(a^{*}, x_{R}\right)$ (plus whatever it announces about $x_{N R}$ ) at stage 1 to the public. Under discretion, the public has more information at stage 1 about what will happen at stage 2 . But the extra information at stage 1 means that the public necessarily has more uncertainty at stage 0 about what will transpire at stage 1 . The critics of central bank discretion are averse to this increased ex ante uncertainty generated by interim central bank information revelation. But as long as the public can make effective use of the information revealed by the central bank's action, this revelation has clear societal benefits.

Let me put this less technically and more directly. The critics of central bank discretion typically treat variations around their preferred rule as largely due to random errors generated by the central bank's incompetence. But it seems much more reasonable to treat those deviations from the rule as purposive responses to information that has not been encoded into the rule. Once we take this perspective, the central bank's freedom to deviate from the rule can be seen as a valuable source of information for the public.

\section{Conclusions}

There is a broad academic macroeconomic consensus that monetary policy should be constrained by rules. In this paper, I argue instead that there are good reasons to believe that societies will achieve better outcomes if central banks are given complete discretion to pursue well-specified goals. Theoretically, discretion allows central banks to take advantage of information about the macroeconomy that is hard to write into rules. Empirically, being willing to deviate more materially from the exit strategy implied by the Taylor rule would have allowed the FOMC to pursue a more rapid recovery from the Great Recession.

I do show that if central banks have a sufficiently large proinflation bias, there exists a set of rules that dominates discretion. (However, it is still not true that all rules dominate discretion.) I argue in this paper that, over the past 20 years, the FOMC has shown little if any proinflation bias. But this claim would be much less true in other periods in history (such as the 1970s). What changes in institutional design have served to reduce the

38. See Taylor (2015, point 4), for example. 
Federal Reserve's inflationary bias to its current low level? I say little about this issue in this paper, beyond referring to increased independence from the White House. However, it is a key question for future research along these lines.

The U.S. House of Representatives has passed legislation that would require the FOMC to treat the Taylor rule as a key benchmark in its decisionmaking about policy. ${ }^{39}$ The analysis in this paper implies that this move by the House is a mistake. It is true that the Taylor rule was arguably associated with good macroeconomic outcomes during a limited period of U.S. economic history. But so was the Riefler-Burgess framework! Enshrining the Taylor rule in a statute would only hamstring the Federal Reserve's response to currently unanticipated events. The House would be much better off requiring the FOMC to communicate a collective forecast for employment and prices, and to explain clearly why policy is not being used to close any gaps between that forecast and the committee's ostensible goals. Congress should reorient its perspective about what constitutes appropriate monetary policy away from the FOMC's choice of its instruments and toward the FOMC's pursuit of its goals. Such a change in focus would incentivize the committee to pursue rapid recoveries in unemployment and inflation, rather than allow it to stick closely to its prior reaction function.

ACKNOWLEDGMENTS I thank Sam Schulhofer-Wohl and Kei-Mu Yi for their comments. I also thank Alan Blinder, William Brainard, Janice Eberly, Emma Ko, David Romer, and Lars Svensson for their comments on drafts.

39. Specifically, see section 2 of H.R. 3189, the Fed Oversight Reform and Modernization Act of 2015. 


\section{References}

Alichi, Ali, Kevin Clinton, Charles Freedman, Ondra Kamenik, Michel Juillard, Douglas Laxton, Jarkko Turunen, and Hou Wang. 2015. "Avoiding Dark Corners: A Robust Monetary Policy Framework for the United States." Working Paper no. 15/134. Washington: International Monetary Fund.

Athey, Susan, Andrew Atkeson, and Patrick J. Kehoe. 2005. "The Optimal Degree of Discretion in Monetary Policy." Econometrica 73, no. 5: 1431-75.

Bernanke, Ben S. 2012. "Monetary Policy since the Onset of the Crisis." Speech given at the Economic Policy Symposium: The Changing Policy Landscape, Federal Reserve Bank of Kansas City, Jackson Hole, Wyo., August 31.

- 2015. "Objections to Federal Reserve Accountability Bill." Remarks given at The Fed in the 21st Century: Independence, Governance, and Accountability, Brookings Institution, Washington, March 2. https://www. youtube.com/watch? $\mathrm{v}=\mathrm{KJmA5JDNpKg} \& \mathrm{t}=42$

Brainard, William C. 1967. "Uncertainty and the Effectiveness of Policy." American Economic Review 57, no. 2: 411-26.

Brunner, Karl, and Allan H. Meltzer. 1968. "What Did We Learn from the Monetary Experience of the United States in the Great Depression?" Canadian Journal of Economics 1, no. 2: 334-48.

Canzoneri, Matthew B. 1985. "Monetary Policy Games and the Role of Private Information." American Economic Review 75, no. 5: 1056-70.

da Costa, Pedro Nicolaci. 2015. "Ben Bernanke Says Fed Already Follows Policy Rule.” Real Time Economics blog. Wall Street Journal, March 2.

Eggertsson, Gauti B., and Michael Woodford. 2003 "The Zero Bound on Interest Rates and Optimal Monetary Policy." Brookings Papers on Economic Activity, no. 1: 139-211.

FOMC (Federal Open Market Committee). 2009a. "Meeting of the Federal Open Market Committee on December 15-16, 2009." Meeting minutes. https://www. federalreserve.gov/monetarypolicy/files/FOMC20091216meeting.pdf

_ 2009b. "Meeting of the Federal Open Market Committee on November 3-4, 2009." Meeting minutes. https://www.federalreserve.gov/monetary policy/files/FOMC20091104meeting.pdf

- 2009c. SEP: Compilation and Summary of Individual Economic Projections, November 3-4. https://www.federalreserve.gov/monetarypolicy/files/ FOMC20091104SEPcompilation.pdf

.2010a. "Conference Call of the Federal Open Market Committee on October 15, 2010." Meeting minutes. https://www.federalreserve.gov/monetary policy/files/FOMC20101015confcall.pdf

2010b. "Meeting of the Federal Open Market Committee on March 16, 2010." Meeting minutes. https://www.federalreserve.gov/monetarypolicy/files/ FOMC20100316meeting.pdf

2010c. "Meeting of the Federal Open Market Committee on November 2-3, 2010." Meeting minutes. https://www.federalreserve.gov/monetary policy/files/FOMC20101103meeting.pdf 
2010d. SEP: Compilation and Summary of Individual Economic Projections, November 2-3. https://www.federalreserve.gov/monetarypolicy/files/ FOMC20101103SEPcompilation.pdf

. 2016. "Statement on Longer-Run Goals and Monetary Policy Strategy." January 26. https://www.federalreserve.gov/monetarypolicy/files/FOMC_ LongerRunGoals_20160126.pdf

Federal Reserve Board staff. 2009a. Current Economic and Financial Conditions, Part 1, Summary and Outlook. Greenbook prepared for the Federal Open Market Committee, October 29. https://www.federalreserve.gov/monetary policy/files/FOMC20091104gbpt120091029.pdf

. 2009b. Monetary Policy Alternatives. Bluebook prepared for the Federal Open Market Committee, October 29. https://www.federalreserve.gov/monetary policy/files/FOMC20091104bluebook20091029.pdf

- 2010a. Report to the FOMC on Economic Conditions and Monetary Policy, Book A, Economic and Financial Conditions: Current Situation and Outlook. Tealbook prepared for the Federal Open Market Committee, October 27. https://www.federalreserve.gov/monetarypolicy/files/FOMC20101103tealbook a20101027.pdf

- 2010b. Report to the FOMC on Economic Conditions and Monetary Policy, Book B, Monetary Policy: Strategies and Alternatives. Tealbook prepared for the Federal Open Market Committee, October 28. https://www.federal reserve.gov/monetarypolicy/files/FOMC20101103tealbookb20101028.pdf

Gagnon, Joseph E. 2009. "The World Needs Further Monetary Ease, Not an Early Exit.” Policy Brief no. 09-22. Washington: Peterson Institute for International Economics.

Hansen, Lars Peter, and Thomas J. Sargent. 2007. Robustness. Princeton University Press.

Hansen, Lars Peter, Robert Lucas, Edward Prescott, and others. 2016. "Statement on Policy Rules Legislation." February 9. http://financialservices.house.gov/ uploadedfiles/020916_taylor_letter_with_signatories_.pdf

Holmström, Bengt. 1984. "On the Theory of Delegation.” In Bayesian Models in Economic Theory, edited by Marcel Boyer and Richard E. Kihlstrom. Amsterdam: North-Holland.

Kocherlakota, Narayana. 2012. "Planning for Liftoff." Speech given at Gogebic Community College, Ironwood, Mich., September 20.

_ 2015a. "Monetary Policy Renormalization." Speech given at the Federal Reserve Bank of Philadelphia Policy Forum: The New Normal for the U.S. Economy, Federal Reserve Bank of Philadelphia, December 4.

—. 2015b. "Rules versus Discretion: A Reconsideration." Speech given at the Korea-America Economic Association, Boston, January 4.

Kydland, Finn E., and Edward C. Prescott. 1977. "Rules Rather than Discretion: The Inconsistency of Optimal Plans." Journal of Political Economy 85, no. 3: 473-92.

Meltzer, Allan H. 2003. A History of the Federal Reserve, Volume 1, 1913-1951. University of Chicago Press. 
2013. "Comments on "Volatile Times and Persistent Conceptual Errors.'" In The Origins, History, and Future of the Federal Reserve: A Return to Jekyll Island, edited by Michael D. Bordo and William Roberds. Cambridge University Press.

Meyer, Laurence H. 1998. "Come with Me to the FOMC." Gillis Lecture, Willamette University, Salem, Ore., April 2.

Reifschneider, David. 2016. "Gauging the Ability of the FOMC to Respond to Future Recessions.” Finance and Economics Discussion Series no. 2016-068. Washington: Board of Governors of the Federal Reserve System.

Svensson, Lars E. O. 1997. "Inflation Forecast Targeting: Implementing and Monitoring Inflation Targets.” European Economic Review 41, no. 6: 1111-46.

_. 2003. "What Is Wrong with Taylor Rules? Using Judgment in Monetary Policy through Targeting Rules." Journal of Economic Literature 41, no. 2: 426-77.

Svensson, Lars E. O., and Robert J. Tetlow. 2005. "Optimal Policy Projections." International Journal of Central Banking 1, no. 3: 177-207.

Taylor, John B. 1993. "Discretion versus Policy Rules in Practice." CarnegieRochester Conference Series on Public Policy 39: 195-214.

1998. “Applying Academic Research on Monetary Policy Rules: An Exercise in Translational Economics.” Manchester School 66, supplement: 1-16.

__ 2015. "Time Inconsistency Is Only One of Many Reasons to Favor Policy Rules.” Economics One blog, September 22. https://economicsone. com/2015/09/22/time-inconsistency-is-only-one-of-many-reasons-to-favorpolicy-rules/

Wallace, Neil. 1981. "A Modigliani-Miller Theorem for Open-Market Operations." American Economic Review 71, no. 3: 267-74.

Walsh, Carl E. 1995. "Optimal Contracts for Central Bankers.” American Economic Review 85, no. 1: 150-67.

Williams, John C. 2013. “A Defense of Moderation in Monetary Policy.” Journal of Macroeconomics 38, pt. B: 137-50.

Woodford, Michael. 2012. "Methods of Policy Accommodation at the Interest-Rate Lower Bound." In Economic Policy Symposium Proceedings: The Changing Policy Landscape. Jackson Hole, Wyo.: Federal Reserve Bank of Kansas City.

Yellen, Janet L. 2015. "Letter to the Honorable Paul Ryan and the Honorable Nancy Pelosi." November 16. http://www.federalreserve.gov/foia/files/ryanpelosi-letter-20151116.pdf

. 2016. "The Federal Reserve's Monetary Policy Toolkit: Past, Present, and Future.” Speech given at the Economic Policy Symposium: Designing Resilient Monetary Policy Frameworks for the Future, Federal Reserve Bank of Kansas City, Jackson Hole, Wyo., August 26. 


\section{Comments and Discussion}

\section{COMMENT BY}

ALAN S. BLINDER This fascinating paper is actually two minipapers, which I take up here in reverse order. The paper's second part is a theoretical discussion of why discretion is better than rules. Its first part is a practical, historical discussion of why the Federal Reserve was, in Narayana Kocherlakota's view, too timid in 2009 and 2010 - and, implicitly, after that as well. The (nonmissing) link between the two parts is Kocherlakota's claim that the Federal Reserve's timidity was, in large measure, due to excessive adherence to the original Taylor rule.

Critiques of the Federal Reserve's monetary policy by an insider are extraordinarily valuable — and very rare. So we should all thank Kocherlakota for writing this paper. My first reaction was to jump for joy. But then I realized two things.

First, the real issue is comparing somewhat incorrect rules to imperfect use of discretion. This is tough (impossible?) to do with mathematical precision; we need human judgment. (Might this be a metaphor for the whole issue?) Second, the link between the two parts, via the Taylor rule, is a bit tenuous since the nominal federal funds rate (henceforth, $i$ ) was constrained to the Federal Reserve's version of "zero" (that is, 0 to 25 basis points) at the times in question. The only Taylor-rule-related issues were when "liftoff" was projected to occur and what path $i$ was projected to follow thereafter. The November 2009 Bluebook had liftoff in 2012; and the November 2010 Tealbook had it in 2014-both far enough in the future to be nearly irrelevant to the decision at hand.

So, in the end, I am still joyful about this paper-but I am not quite jumping.

I start with Kocherlakota's theory minipaper. The traditional trade-off in theoretical papers between rules and discretion in monetary policy pits 
the alleged inflation bias of central banks, which points toward adopting rules, against private information possessed by the central bank, which points toward the use of discretion (Canzoneri 1985). By the way, kudos to Kocherlakota for writing here about "nonrulable information" rather than "private information," because the latter is, in my view, rarely large or important. When it comes to the macroeconomy, outsiders know almost everything the central bank does.

In Kocherlakota's version, the inflation bias shows up as an inflation target that is too high: $\pi_{C B}>\pi_{S O C}$. Assumptions like that have never made sense to me. Do not real governments typically appoint "conservative central bankers," that is, men and women with $\pi_{C B}<\pi_{S O C}$, perhaps for Kenneth Rogoff's (1985) reasons?

Furthermore, it is worth remembering that Robert Barro and David Gordon (1983), following Finn Kydland and Edward Prescott (1977), sought to explain the rising inflation rates of, say, the period 1965-80. But the time inconsistency theory they use predicts inflation that is too high, not rising inflation. In addition, the history of inflation since 1980 has been rather different, to put it mildly. Let us also note the utterly obvious point that the sharp disinflation in the United States in the early 1980s stemmed not from rules but from Paul Volcker's use of discretion-and his steely resolve. Finally, Vietnam War spending, supply shocks, and Volcker provide a far more convincing explanation for both why inflation rose from 1965 to 1980 and fell thereafter (Blinder and Rudd 2013).

Supposing that both bias and nonrulable information exist, Kocherlakota's main conclusion is not that rules are better than discretion but rather that very, very good rules can be better than discretion only if the inflation bias is relatively large and the variance of rulable shocks is relatively large. Kocherlakota doubts that the inequality runs this way, arguing that there is little inflation bias at the Federal Reserve. I agree, based on both the abovementioned "natural selection" of central bankers and the oath of office that all Federal Reserve governors take-which is likely a more powerful commitment device than the game-theoretic versions of that idea one finds in the academic literature. Furthermore, there is obviously much nonrulable information in the real world. The question is: Is it quantitatively important? My answer is that, at certain crucial times, it is tremendously important. Just ask Ben Bernanke.

Two final thoughts on the rules-versus-discretion debate, which Kocherlakota does not bring up. First, we probably do not live in a stationary environment, which severely undermines the case for rules. Second, however, discretion is probably not practiced perfectly, despite the 
indubitable brilliance of the Federal Open Market Committee's (FOMC's) members - which undermines the case for discretion. As I said, mathematics will not resolve the rules-versus-discretion debate.

I turn now to the history minipaper, in which the two most important tables are Kocherlakota's tables 1 and 2.

Kocherlakota could almost stop his argument there. The two tables display the FOMC's low aspiration levels in both November 2009 and November 2010. Even three years ahead-which, according to most empirical estimates of lags, is enough time for monetary policy to have had its major effects - the committee was projecting (or was it hoping?) to close only a fraction of the gaps between the actual and target inflation and unemployment rates. As Kocherlakota says, the FOMC seemed to be giving up too easily, including rejecting — by overwhelming margins—staff options for more aggressive quantitative easing or forward guidance.

I knew the FOMC was hawkish at the time. For example, in its infamous August 2007 statement, issued as the financial world teetered on the brink (and would soon fall off), the committee decided that its "predominant policy concern remains the risk that inflation will fail to moderate as expected" (FOMC 2007). What? many of us outsiders wondered at the time. Are they really fiddling with inflation while the economy threatens to burn? Later, in July 2009, Chairman Bernanke (2009) told Congress, "The FOMC has been devoting considerable attention to issues relating to its exit strategy." Considerable attention to exit? Shortly after the trough of the worst recession since the 1930s? Even so, I was surprised to learn in this paper that not a single FOMC member supported the staff's more aggressive options.

Kocherlakota's key claim is that more "stimulative steps received little support within the FOMC"- at least partly because they would have led to a larger deviation from the Taylor rule's prescriptions. But which Taylor rule was that? The Federal Reserve Board staff's basic rule at the time was

$$
i=2.5+\pi-1.1\left(U-U^{*}\right)+0.5(\pi-2) .
$$

Note a few things here. First, this equation is not estimated. Rather, it is a modest adaptation of John Taylor's (1993) original-also not estimated-version; for example, the unemployment gap replaces the GDP gap. If the Federal Reserve's reaction function had been estimated, $i_{t-1}$ would surely have been a highly significant variable, which would have slowed down any projected rate hikes. Second, the neutral real funds rate of 2.5 percent looks a bit high — which also made the projected funds rate path higher. 
In my day on the FOMC, which was admittedly a long time ago, we routinely saw results from $n$ different Taylor rules. (I cannot recall the value of $n$, but it was much larger than 1.) Among other things, these equations used either the unemployment gap or the GDP gap, offered different measures of each, used alternative measures of inflation, and (if estimated) had different coefficients-including a nonzero coefficient on $i_{t-1}$. The range of recommended $i$ produced by these $n$ rules was normally wide-maybe 150 to 250 basis points. Was this not also true in 2009 and 2010? Had there been technological regress at the Federal Reserve? ${ }^{1}$

So I was pretty shocked to learn from this paper that one particular Taylor rule held that much sway. But remember, $i$ was constrained to near zero all this time. So how important could any Taylor rule have been for a committee that always makes just one interest rate decision at a time? That said, I do agree with Kocherlakota that the Federal Reserve was too timid and hawkish during the period in question. Yet there are at least two very important buts.

First, once the federal funds rate hit near zero in December 2008, and after the first stages of quantitative easing in early 2009 were completed, the FOMC was down to pretty weak instruments. So there was not much more the Federal Reserve could have done to boost aggregate demandthough there is some, which is Kocherlakota's criticism.

Second, we should grade policymakers on a curve. The FOMC was then operating in uncharted waters, and most other crisis-afflicted central banks performed worse. That is why I come here today not to bury Chairman Bernanke and Vice Chairman Kohn in criticism, but to praise them.

\section{REFERENCES FOR THE BLINDER COMMENT}

Barro, Robert J., and David B. Gordon. 1983. "A Positive Theory of Monetary Policy in a Natural Rate Model." Journal of Political Economy 91, no. 4: 589-610.

Bernanke, Ben S. 2009. "Semiannual Monetary Policy Report to the Congress." Testimony before the Committee on Financial Services, U.S. House of Representatives, July 21, and the Committee on Banking, Housing, and Urban Affairs, U.S. Senate, July 22.

Blinder, Alan S., and Jeremy B. Rudd. 2013. "The Supply-Shock Explanation of the Great Stagflation Revisited." In The Great Inflation: The Rebirth of Modern Central Banking, edited by Michael D. Bordo and Athanasios Orphanides. University of Chicago Press.

1. At the Fall 2016 Brookings Papers conference, Donald Kohn assured me and others that the FOMC was still presented with a variety of Taylor rules in 2009 and 2010. 
Canzoneri, Matthew B. 1985. "Monetary Policy Games and the Role of Private Information." American Economic Review 75, no. 5: 1056-70.

FOMC (Federal Open Market Committee). 2007. "FOMC Statement.” Monetary Policy Press Release, August 7. https://www.federalreserve.gov/newsevents/ press/monetary/20070807a.htm

Kydland, Finn E., and Edward C. Prescott. 1977. "Rules Rather Than Discretion: The Inconsistency of Optimal Plans." Journal of Political Economy 85, no. 3: 473-92.

Rogoff, Kenneth. 1985. "The Optimal Degree of Commitment to an Intermediate Monetary Target." Quarterly Journal of Economics 100, no. 4: 1169-89.

Taylor, John B. 1993. "Discretion versus Policy Rules in Practice." CarnegieRochester Conference Series on Public Policy 39: 195-214.

\section{COMMENT BY}

LARS E. O. SVENSSON In this fine paper, Narayana Kocherlakota argues that the Federal Open Market Committee's (FOMC's) ambition during the 2009-10 period to achieve price stability and maximum employment was too limited and that its policy was not sufficiently expansionary, to a considerable extent because the FOMC was influenced by the Taylor rule. In particular, he shows that a more expansionary policy would have been feasible and that staff simulations of optimal policy, which are included in the material distributed before meetings to FOMC participants, were more expansionary than the policies chosen by the FOMC. In a theoretical section, Kocherlakota shows that, if a central bank's objectives are not too different from society's, central bank discretion is better than a commitment to a simple instrument rule, such as a Taylor rule. This is because the central bank can then take relevant private information into account in its decisions.

Kocherlakota then shows that because there is no evidence that the FOMC has objectives too different from society's, discretion would be better than a Taylor rule for the FOMC. He finally considers the Fed Oversight Reform and Modernization Act, legislation passed by the U.S. House of Representatives that would require the FOMC to treat the Taylor rule as a key benchmark in its decisionmaking about policy. He finds that the analysis of his paper implies that this move by the House is a mistake, writing:

The House would be much better off requiring the FOMC to communicate a collective forecast for employment and prices, and to explain clearly why policy is not being used to close any gaps between that forecast and the committee's ostensible goals. Congress should reorient its perspective about what constitutes appropriate monetary policy away from the FOMC's choice of its instruments and 
toward the FOMC's pursuit of its goals. Such a change in focus would incentivize the committee to pursue rapid recoveries in unemployment and inflation, rather than allow it to stick closely to its prior reaction function.

I could not agree more with Kocherlakota's conclusion about the U.S. Congress and how it should reorient its perspective about what constitutes appropriate monetary policy. I also find his comments about FOMC deliberations and discussions extremely interesting and valuable.

In the rest of this discussion, I say a few words about FOMC policy and briefly contrast its policy with that of the central bank of Sweden, Sveriges Riksbank, in 2010. Furthermore, I question the statement that there is a broad consensus that central banks should closely follow Taylor-type instrument rules and argue that forecast targeting is a more appropriate and realistic monetary policy, as clearly articulated by Ben Bernanke.

FEDERAL RESERVE POLICY FROM 2009 TO 2010 I agree with Kocherlakota that it would have been technically possible for the FOMC to conduct more expansionary policy during the 2009-10 period—as, for instance, the staff's optimal policy projections show. But I am not convinced that this was necessarily because the FOMC was overly influenced and constrained by the Taylor rule. For instance, I did not see much evidence of this in the transcripts of the November 2009 and November 2010 FOMC meetings. I did not find any mention of the Taylor rule in the 2009 transcripts, and I found only brief references to it on 5 of 238 pages in the 2010 transcripts.

From an external observer's point of view, it seems that constraints in the form of internal dissent in the FOMC, along with external opposition from Congress, may have played a role and prevented a more expansionary policy. Certainly, the apparent FOMC tradition of largely reaching a consensus rather than making majority decisions and related limitations on the acceptable number of dissenters are likely to give the marginal dissenter a strong position and could lead to inertia in decisionmaking. Also, opposition and even hostility from Congress and a related potential threat to the independence of the Federal Reserve could have limited the scope for policy actions. In 2011, I wrote a paper comparing the monetary policies of the Federal Reserve and the Riksbank during the 2010-11 period, and I could not exclude the possibility that Federal Reserve policy was roughly consistent with optimization under various constraints, including opposition from Congress (Svensson 2011b).

Furthermore, I think it is important to retain a sense of proportion about Federal Reserve policy during the Great Recession. I think it is fair to say that Ben Bernanke and his colleagues at the FOMC most likely saved the United States, and probably the world, from having the Great Recession 
turn into the Second Great Depression. Because Bernanke trusted his judgment and his previous research on the Great Depression and on unconventional monetary policy with the federal funds rate at its lower bound (for instance, Bernanke, Reinhart, and Sack 2004), he led Federal Reserve monetary policy out onto a limb to save the U.S. economy. Without this bold action, the United States and world economic developments would have been inconceivably worse.

An international perspective can help one to retain a sense of proportion. The FOMC does pretty well in such a comparison. In particular, it does much better than the Riksbank. In June 2010, the FOMC's and Riksbank's forecasts of inflation and unemployment were very similar. The inflation forecasts were both below 2 percent (the implicit and explicit inflation targets of the FOMC and the Riksbank, respectively), and the unemployment forecasts were both far above a long-run sustainable unemployment rate (my figure 1). In this situation, the FOMC kept the federal funds rate at its perceived lower bound, prepared the second round of quantitative easing (QE2), communicated further policy easing, and launched QE2 later in the fall of 2010. With reference to these FOMC forecasts, Bernanke (2010) said, "Given the committee's objectives, there would appear-all else being equal — to be a case for further action." He certainly did not mean a case for policy tightening. But this is precisely what the Riksbank did in this situation.

The majority of the Riksbank's Executive Board raised the policy rate from 25 basis points in June 2010 to 200 basis points in July 2011 (my figure 2, top left panel). ${ }^{1}$ Whereas U.S. core personal consumption expenditures (PCE) inflation stayed above 1 percent during the next few years, Swedish inflation fell rapidly, to near zero (my figure 2, top right panel). Whereas the real federal funds rate stayed substantially below zero, the Riksbank's real policy rate thus increased several percentage points (my figure 2, bottom left panel). Whereas the U.S. unemployment rate came down quickly in the next few years, the Swedish unemployment rate stayed up (my figure 2, bottom right panel). Imagine if the FOMC had conducted a policy similar to that of the Riksbank!

A BROAD CONSENSUS THAT CENTRAL BANKS SHOULD FOLLOW TAYLOR RULES? WHAT ABOUT FORECAST TARGETING? Is there a broad consensus that central banks should follow Taylor rules? First, a Taylor-type rule implies that the

1. As a deputy governor of the Riksbank from 2007 to 2013, I dissented in favor of easier policy at every policy meeting starting in April 2009. Svensson (2013) summarizes my lessons from these years as a policymaker. 
Figure 1. The FOMC's and the Riksbank's June 2010 Forecasts, 2008-13

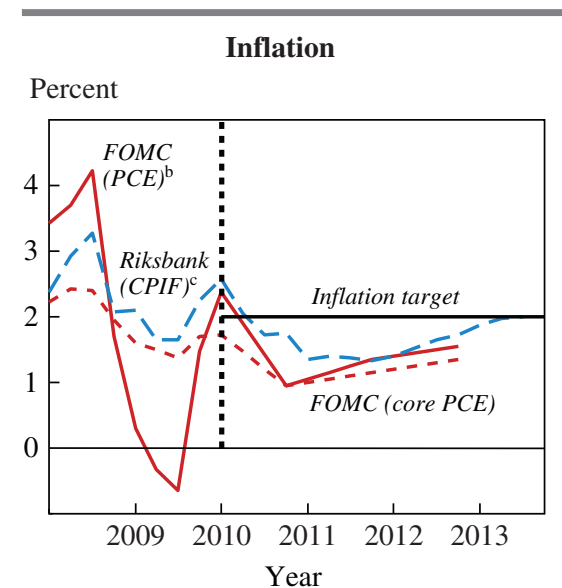

\section{Unemployment}

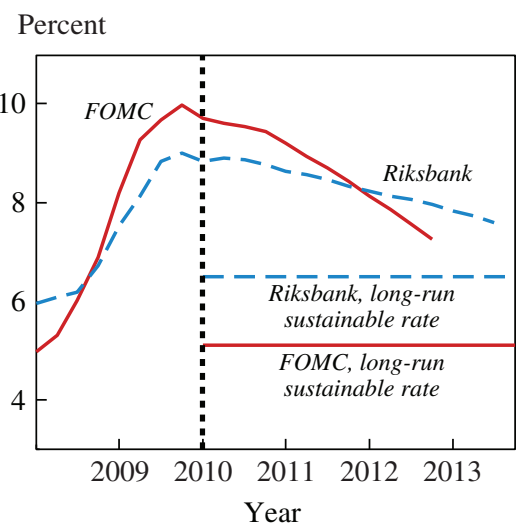

Source: Svensson (2011b)

a. The vertical line in each figure marks the first quarter of 2010 , the last quarter for which inflation and unemployment outcomes were available during the June 2010 meetings of the FOMC and the Riksbank. Data to the left of the vertical line were realized, and data to the right were forecasts.

b. PCE stands for personal consumption expenditures.

c. The CPIF is the consumer price index with a constant mortgage rate.

central bank is only responding to current inflation and output. ${ }^{2}$ It is pretty obvious that real-world central banks respond to much more information than inflation and output and thus do not mechanically follow Taylor-type rules. Furthermore, it is obvious that Taylor rules are not optimal. An optimal policy responds to all relevant state variables (including all relevant information), and there are many more relevant state variables and much more relevant information than current inflation and output (Svensson 2003).

Second, though it is true that many papers in monetary macroeconomics assume that monetary policy mechanically follows a Taylor-type rule, I believe that this is to a large extent for convenience. Incidentally, the same papers often assume that households optimize in a rather sophisticated way, instead of mechanically following a consumption function. This is true despite the fact that central banks have simple objectives and usually employ many $\mathrm{Ph} . \mathrm{D}$. economists who specialize in optimal monetary policy. In contrast, households have complicated objectives and employ no

2. To be precise, a Taylor rule responds to the output gap, not just to output. Estimating potential output involves a whole set of difficulties, not discussed here but in Svensson (2011b). 
Figure 2. Interest, Inflation, and Unemployment Rates in the United States, Sweden, and Selected Other Economies, 2000-16

Interest rates

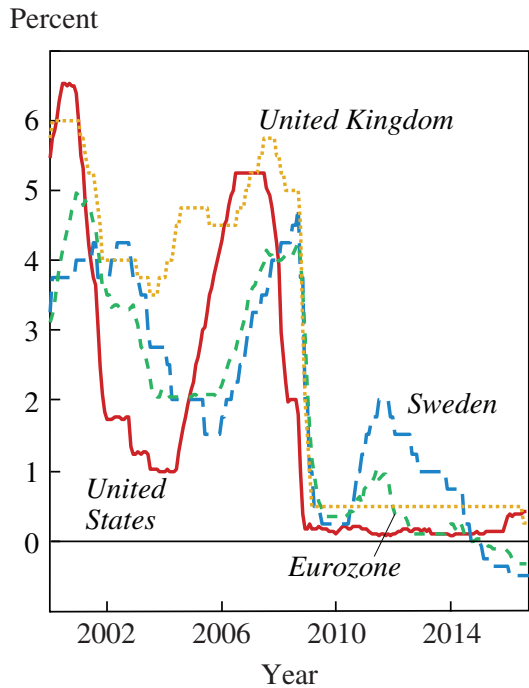

\section{Real interest rates ${ }^{\mathrm{b}}$}

Percent

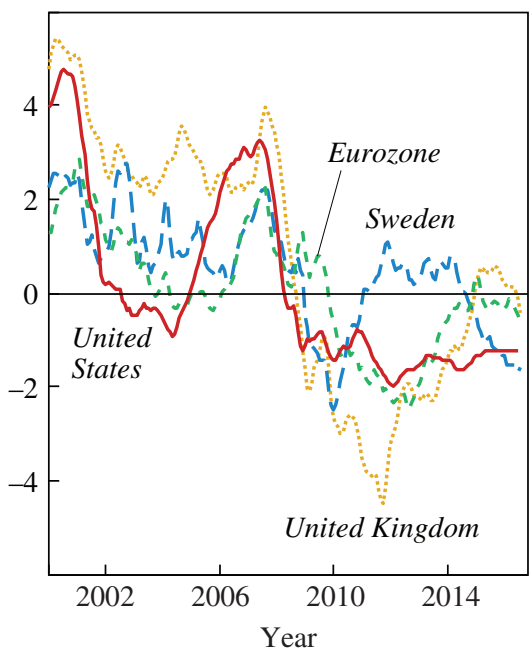

Inflation rates $^{\mathrm{a}}$

Percent

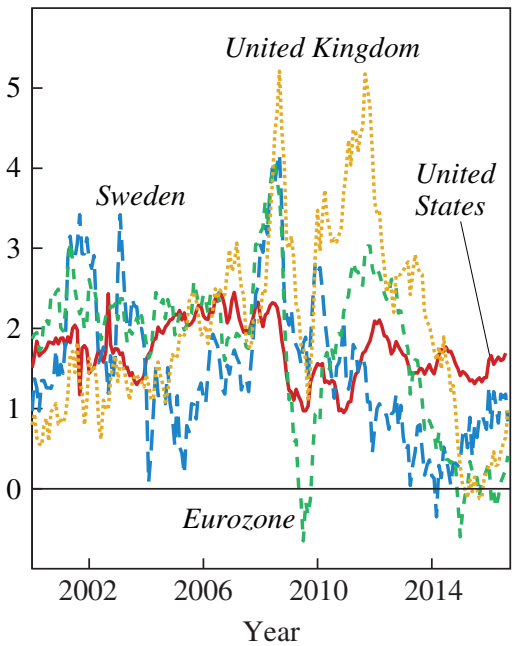

\section{Unemployment rates}

Percent

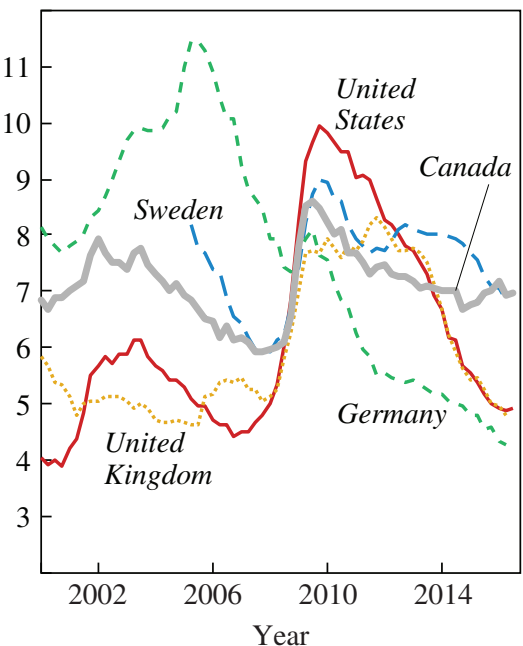

Source: DataStream.

a. Inflation is measured by the core PCE for the United States, and by the harmonized index of consumer prices for Sweden, the eurozone, and the United Kingdom.

b. Real interest rates are 3-month moving averages of the difference between the nominal interest rates and the inflation rates. 
specialists in optimal policy. Which are more likely to display optimizing behavior-households or central banks (Svensson 2003)?

Generally, I do not think that "rules versus discretion" is the best way of phrasing the problem. Discretion with stable objectives and stable constraints also results in systematic, rule-like policy. Instead, I think it is better to think in terms of different kinds of rules, such as instrument rules versus targeting rules. Central banks' real-world commitments are not to follow a particular instrument rule but rather to achieve their targets, which can be seen as "targeting rules." Achieving targets is the rule.

Ben Bernanke (2015b) has put it very well, as quoted by Kocherlakota: "The Fed has a rule. The Fed's rule is that we will go for a two percent inflation rate. We will go for the natural rate of unemployment. We will put equal weight on those two things. We will give you information about our projection, our interest rates. That is a rule."

What Bernanke is talking about here can more precisely be termed "forecast targeting." This can be described as choosing a policy rate and policy-rate path so that the resulting forecasts of the target variablesinflation and unemployment-will "look good," meaning stabilizing inflation around the target and unemployment around its long-run sustainable rate. Forecast targeting, rather than Taylor-type rules, is further discussed and promoted by Bernanke (2004, 2015a), Donald Kohn (2007), Jan Qvigstad (2005), Michael Woodford (2007), and myself (Svensson 1997, 2011a).

With regard to the quotation given above, Kocherlakota criticizes Bernanke for not providing any target horizon: "As a result, his description is equally consistent with a plan to return inflation to target over 1 year, 2 years, or 20 years." But if the dual mandate, as in the FOMC staff's optimal policy projections, is reasonably interpreted as having a quadratic loss function with equal weight on squared deviations of inflation from the target and unemployment from its long-run sustainable rate, a fixed target horizon is inappropriate. The horizons at which inflation and unemployment optimally get close to, respectively, the target and the long-run sustainable rate then depends on the initial situation and the shocks. ${ }^{3}$ That the forecasts of inflation and unemployment "look good" means that they achieve an efficient trade-off between inflation and unemployment gap stability, with approximately equal weight on each. For all practical purposes, this is equivalent to the statement that the FOMC "follows a balanced

3. Because optimal policy implies that inflation and unemployment asymptotically approach the inflation target and the long-run sustainable rate of unemployment, "get close to" is more correct than "return to." 
approach in promoting [its objectives], taking into account the magnitude of the deviations and the potentially different time horizons over which employment and inflation are projected to return to levels judged consistent with its mandate" (FOMC 2016). ${ }^{4}$

Forecast targeting then implies that the central bank responds and adjusts its policy in response to any information that materially affects the forecasts of inflation and unemployment. This information includes much more than new information about current inflation and output. Indeed, one can say that the new information is filtered through the forecast, and the new information that is relevant for the policy settings is the information that shifts the forecasts. And current inflation and output are then relevant for policy only to the extent that they affect the forecasts. ${ }^{5}$

Thus, several policymakers and researchers have argued against Taylortype rules and in favor of what can be called forecast targeting. I strongly welcome Kocherlakota to this group.

\section{REFERENCES FOR THE SVENSSON COMMENT}

Bernanke, Ben S. 2004. "The Logic of Monetary Policy." Speech given at the National Economists Club, Washington, December 2.

2010. "Monetary Policy Objectives and Tools in a Low-Inflation Environment." Speech given at the Revisiting Monetary Policy in a Low-Inflation Environment Conference, Federal Reserve Bank of Boston, Boston, October 15.

—. 2015a. "Monetary Policy in the Future." Blog post, April 15. Washington: Brookings Institution.

. 2015b. "Objections to Federal Reserve Accountability Bill." Remarks given at The Fed in the 21st Century: Independence, Governance, and Accountability, Brookings Institution, Washington, March 2. https://www.youtube.com/ watch? $=\mathrm{KJmA}$ JDNpKg\&t=42

Bernanke, Ben S., Vincent R. Reinhart, and Brian P. Sack. 2004. "Monetary Policy Alternatives at the Zero Bound: An Empirical Assessment." Brookings Papers on Economic Activity, no. 2: 1-78.

4. Jan Qvigstad, former deputy governor of the central bank of Norway, Norges Bank, has formulated the "Qvigstad rule," which, when applied to inflation and unemployment, implies that the forecasted inflation and unemployment gaps should have the same sign (Qvigstad 2005).

5. It is important that the relevant information includes all information that materially affects the forecasts, not only any private information of the central bank, the case dealt with by Kocherlakota. Also, transparent monetary policy implies that any of the central bank's relevant private information should soon, through central bank communication, become public information. 
FOMC (Federal Open Market Committee). 2016. "Statement on Longer-Run Goals and Monetary Policy Strategy." January 26. https://www.federalreserve. gov/monetarypolicy/files/FOMC_LongerRunGoals_20160126.pdf

Kohn, Donald L. 2007. "John Taylor Rules." Speech given at the Conference on John Taylor's Contributions to Monetary Theory and Policy, Federal Reserve Bank of Dallas, Dallas, October 12.

Qvigstad, Jan F. 2005. "When Does an Interest Rate Path 'Look Good'? Criteria for an Appropriate Future Interest Rate Path-A Practician's Approach.” Staff Memo no. 2005/6. Norges Bank.

Svensson, Lars E. O. 1997. "Inflation Forecast Targeting: Implementing and Monitoring Inflation Targets." European Economic Review 41, no. 6: 1111-46.

—. 2003. "What Is Wrong with Taylor Rules? Using Judgment in Monetary Policy through Targeting Rules." Journal of Economic Literature 41, no. 2: 426-77.

. 2011a. "Inflation Targeting." In Handbook of Monetary Economics, Volume $3 B$, edited by Benjamin M. Friedman and Michael Woodford. Amsterdam: North-Holland.

— 2011b. "Practical Monetary Policy: Examples from Sweden and the United States." Brookings Papers on Economic Activity, Fall: 289-332.

—. 2013. "Some Lessons from Six Years of Practical Inflation Targeting." Sveriges Riksbank Economic Review, no. 3: 29-80.

Woodford, Michael. 2007. "The Case for Forecast Targeting as a Monetary Policy Strategy." Journal of Economic Perspectives 21, no. 4: 3-24.

GENERAL DISCUSSION Ben Bernanke was the first to speak, and he agreed with the paper's main premise- that the Federal Reserve's policies should not be constrained by the Taylor rule. He prefers a forecast-based rule-or, more generally, a forecast-based framework-that gives monetary policymakers a coherent structure for formulating and communicating policy, but allows the central bank flexibility to respond to economic developments that cannot be fully captured by a predetermined rule. He noted, moreover, that the Taylor rule is not fully specified in practice because it depends on unobservables. Specifically, the rule depends on assumptions about (i) the natural rate of interest and (ii) the natural rate of unemployment, both of which are uncertain and variable. It would certainly be impossible, Bernanke contended, to get the Federal Open Market Committee (FOMC) to agree on point estimates of the natural rates of interest and unemployment at any point in time. Therefore, he concluded, it would not be workable to use the Taylor rule as either a legislative constraint or as anything other than a broad benchmark for policymakers. 
In his remarks, Kocherlakota had argued that the FOMC countenanced a slow recovery in the 2009-10 period by relying on the Taylor rule as a guide to implementing its plans to remove monetary accommodation. Bernanke did not see the Taylor rule as playing any such role. He saw instead two reasons why the FOMC was not even more aggressive during that period, despite the slow expected pace of recovery. First, given that the 2007-09 financial crisis led to the worst, most catastrophic decline in output and the most chaotic financial conditions since the Great Depression, there were at the time legitimate questions about how quickly the economy would be able to recover, no matter what the Federal Reserve did. Projecting a slow recovery may have simply reflected realism about the powers of monetary policy in such a situation. Second, by early 2009 the Federal Reserve had already lowered interest rates to near zero, and monetary policymakers were using tools with which they had comparatively little experience, and whose effects and potential costs were uncertain. Bernanke recalled that, during his time as chairman of the Federal Reserve, whenever he discussed these tools at press conferences or when giving testimony, particularly regarding large-scale asset purchases, he always listed the possible costs associated with them, including various types of risk-fiscal, market, inflation, and financial instability. If one believed that a certain policy would have benefits but might also involve costs, one would presumably implement the policy more cautiously than if those costs were either nonexistent or at least better understood.

Part of Kocherlakota's argument could be understood to mean that, instead of doing more large-scale asset purchases, the Federal Reserve should have done more forward guidance. In retrospect, Bernanke conceded that Kocherlakota might be right in principle, but-as discussant Alan Blinder pointed out - to have made a difference, the forward guidance would have had to have been about policies expected three or four years into the future. It is not certain whether such guidance would have been credible or effective. Bernanke noted that every statement from the FOMC during the 2009-10 period included a phrase noting that the committee anticipated exceptionally low levels of the federal funds rate for an extended period. So the FOMC did give qualitative forward guidance early on, though it did not give quantitative guidance until later.

Bernanke had a few final observations. First, Kocherlakota had claimed that at the 2009-10 FOMC meetings, staff members had suggested more aggressive policy options - both on quantitative easing and forward guidance-but there had been little support for those options on the committee. Kocherlakota saw that as confirmation that the FOMC actively 
rejected more expansionary policies. Bernanke contended that that was not a fair interpretation of the facts. It was normal practice for the staff, he said, to offer both more aggressive and less aggressive options around the central policy scenario as a way of helping the FOMC calibrate policy impacts. That is how the staff viewed its role. One could just as easily (and incorrectly) conclude that the FOMC was too dovish because it also rejected more hawkish options routinely presented by the staff.

Finally, Bernanke responded to the argument that the FOMC spoke prematurely about its exit strategy. While the FOMC did consider the tools it would need to exit from its accommodative policies, especially quantitative easing, it did so in the spirit of responsible planning, not because it considered exit imminent. Indeed, to maintain market confidence and avoid the possibility of congressional intervention, it was important to explain how the Federal Reserve's policies could safely be unwound when that became necessary. With this goal in mind, Bernanke wrote an op-ed for the Wall Street Journal and he gave special testimony on the issue before Representative Barney Frank's House Committee on Financial Services. ${ }^{1}$ Of course, policy remained very accommodative throughout this period, with the second round of quantitative easing coming later in 2010.

Justin Wolfers wondered what timidity on the part of the Federal Reserve says about rules versus discretion. He thought that Kocherlakota made a very strong case for why the Federal Reserve was excessively timid. If the Federal Reserve was predicting low inflation and high unemployment, under appropriate policy, it must mean that monetary policymakers thought these things were appropriate—or at least more appropriate than aggressive monetary policy. Wolfers asserted that if this was the result of monetary policymakers following a rule, then it follows that the excessive timidity is caused by a bad rule, so rules are bad and discretion is good. If the timidity is caused by something else, then a completely different conclusion follows. If the timidity was caused by the sociology of an organization, by the psychology of central bankers, by the self-selection of the types of people who become central bankers (who are naturally cautious types), or by political pressure-for instance, when Rick Perry says he will "rough you up," or Barney Frank says he will revoke your powers - then this is

1. Ben Bernanke, “The Fed's Exit Strategy,” Wall Street Journal, July 21, 2009; Ben S. Bernanke, "Federal Reserve's Exit Strategy," testimony before the Committee on Financial Services, U.S. House of Representatives, March 25, 2010 (https://www.federalreserve.gov/ newsevents/testimony/bernanke20100325a.htm). 
actually a case for a rule. If the failures are due to human or institutional failures, a rule (more aggressive than the Taylor rule) could offset them.

Frederic Mishkin suggested that what Kocherlakota was getting at was "constrained discretion," a phrase Mishkin and Bernanke coined in their research on inflation targeting. Constrained discretion could affect the trade-off between the inflation bias and the benefits of discretion. He suggested that one of the reasons why the inflation bias did fall so much was because the central banks changed their communication in order to constrain the discretion.

One issue for thinking about following a Taylor rule is that any rule one might put in place would keep changing, for two reasons. The first would be unforeseen circumstances. Mishkin praised Bernanke for recognizing the severity of the impending financial crisis as early as August 2007. According to the Taylor rule, the Federal Reserve should then have raised interest rates because inflation was rising, but in fact it did the opposite because it recognized that something unforeseen was affecting the economy. Second, policymakers are continually learning about how the economy works. When institutions have followed rules slavishly, they have gotten into real trouble. One classic case was when the Swiss National Bank unwaveringly kept following a monetary-base growth rate rule when the process of making interbank payments using the monetary base was changing. The result was that following the rule produced very bad outcomes. If monetary policymakers had taken account of this change, they would have changed the rule. Mishkin asserted that instead of adhering to an unchanging rule, monetary policymakers should talk about what they think is going to happen to the economy and how they would react, and that the Federal Reserve had not been doing as good a job at this as other central banks.

Finally, Mishkin suggested that there was another alternative to the Taylor rule as the explanation for why the Federal Reserve and other central banks had been so timid. He asserted that there might be a "disease" in central banking — a central bank groupthink — what he calls "inflation phobia." That is, he believes central bankers are too concerned about ever exceeding the inflation target. If monetary policymakers are afraid of exceeding the inflation target, there will actually be a negative inflation bias. A good inflation target, he asserted, is one where it is OK to be slightly above it or below it. He was happy to see the Federal Reserve commit to doing this in its statement. However, he argued that there may be a strong case-given inflation targeting's past undershoots-for central banks to try to temporarily exceed the target. This could be done by pursuing the goal of having the 
central bank hit the inflation target over an average period, as is done by the Reserve Bank of Australia.

Donald Kohn wanted to advocate for a few of the points made by Bernanke. "That's my role as vice chairman," he joked. First: Why the timidity? He believed there were genuine questions about the balance of costs and benefits vis-à-vis taking more aggressive action, such as more quantitative easing or extended forward guidance. After all, there was a sense that this was going to be a drawn-out process. There needed to be a balance sheet adjustment in the private sector-pushing it harder might have helped a little-and there were potential costs in financial stability. He did not think this resulted from the psychology of the people involved or the political pressure on policymakers, as Wolfers had suggested. Instead, real economic questions about the costs and benefits led policymakers to not take more aggressive action.

Second, Kohn remarked broadly on the role of the Federal Reserve Board's staff. The Taylor rule, he noted, is what is used to extend the staff's judgmental forecasts, which extend only a couple of years into the future. The staff uses the Federal Reserve's model, with the Taylor rule embedded in it, to extend that forecast a few more years. Kohn believed it was actually helpful to be very mechanical and transparent about how a policy was extended. The role of the staff, in his view, ought to be to present its best judgment, and not be even seen as trying to steer the committee in one particular way. From his own experience, Kohn had sensed that a number of the FOMC's members were very sensitive to the notion that the staff was trying to steer them in any particular direction. The staff's judgment is mainly seen in the forecasts of inflation, output, and unemployment, and much less in the actual policy, which is for the committee to decide. The FOMC's members have access to the Tealbooks and their predecessor staff documents, which contain a range of potential estimates for unobservable variables, along with various simulations of optimal policy. The point here is that the FOMC's members had much information they could use in choosing different policies. All this is to say that Kohn believed there was no way one could argue that the staff's Taylor rule constrained the FOMC's policy prescriptions to be too tight. On the contrary, the information presented by Kocherlakota suggested that many members actually seemed to want tighter policies than the staff was giving them.

Valerie Ramey questioned the implicit assumption that, if the Federal Reserve had acted more aggressively, unemployment would have come down more quickly. She cited a paper by Silvana Tenreyro and Gregory Thwaites that revives the older idea that there is asymmetry in the effects 
of monetary policy. ${ }^{2}$ Although monetary policy is very effective at getting into a recession, it is very bad at getting out of one. If the Federal Reserve had done everything possible, how much more quickly would unemployment really have fallen?

George Perry complimented Kocherlakota and his discussants for his excellent paper and comments but insisted that everyone was being much too polite. He found the case for discretion over rules to be even stronger and simpler than what was being implied. The Federal Reserve's dual mandate is to provide high employment and low inflation, and there is always leeway in emphasizing one goal or the other. The idea of using rules to regulate the interest rate originated with the idea that a politicized Federal Reserve would risk too much inflation by being to expansionary. In fact, Perry noted, history provides little or no cause to question the Federal Reserve's political independence or its commitment to both parts of its mandate. Since the Federal Reserve gained its independence in 1951, there has only been one episode of excessive inflation in the 1970s. But this episode came from war, big oil price shocks, and an institutional structure prone to wage-price spirals; it did not originate with reckless Federal Reserve policy. Indeed, the Federal Reserve's tightening of monetary policy helped to unseat two presidents: Gerald Ford, after a tightening in response to OPEC's quadrupling of oil prices at the end of 1973; and Jimmy Carter after tightening in response to the second oil price shock in 1979.

But if the fear of a reckless or politicized Federal Reserve has little or no basis in history, what about the idea that rules may simply do better, an idea encouraged by the fact that politicians and market players love to criticize the Federal Reserve. In the real world, the opposite is almost surely true: Informed discretionary policy should always outperform rules. For one thing, the economy and its institutions continually evolve. Rules do not keep up while policymakers with discretion can hope to, and quite apart from such evolutionary changes, as Kocherlakota notes, many of the shocks and surprises that challenge monetary policy are not rulable. Perry contended that these are the events that make expert discretionary policymaking invaluable, times that challenge Federal Reserve officials and staff to figure out what the data are telling them, and what response is appropriate. In short, they are times when especially skilled people should be making the decisions.

2. Silvana Tenreyro and Gregory Thwaites, "Pushing on a String: U.S. Monetary Policy Is Less Powerful in Recessions," American Economic Journal: Macroeconomics 8, no. 4 (2016): 43-74. 
Phillip Swagel thought it was useful to keep in mind some of the background of what was going on in the fall of 2009 to provide a context for the FOMC's actions. For one, the Congressional Budget Office's August 2009 forecasts were still for decent growth. This forecast was off, with growth not as high as projected. But when the fiscal stimulus was enacted, there were high hopes for it. In retrospect, people criticized the Obama administration's actions, but in real time it seems unfair to do so. In the same sense, criticizing the FOMC's actions in retrospect misses the context and feelings at the time.

Robert Gordon expressed skepticism about announcement effects and forward guidance, both in the context of two considerations. The first is the translation from what the Federal Reserve controls - the federal funds rate - to what really matters for many expenditures-the 10-year Treasury bond rate. Over the last few years, the Federal Reserve's governors have frequently predicted that the federal funds rate would be going up substantially over the subsequent 18 months. In fact, however, what has happened is that the 10-year Treasury bond rate has come down because nobody believed these forecasts. The markets look at what actually happens, Gordon explained, not what the Federal Reserve says is going to happen, except over a few blips lasting only for a short period. Back in 2009, the Federal Reserve stated that the federal funds rate would be low for an extended period of time, but the markets did not believe that in the same way-until they saw, year after year, that the federal funds rate really did stay low, and that is what brought down the 10-year Treasury bond rate.

As an application of the principle that expectations respond to observed reality rather than the Federal Reserve's pronouncements, Gordon proposed thinking about a promise by the Federal Reserve to switch from a 2 percent inflation target to, say, a 4 percent target. "I would be skeptical that the Fed, by saying that, would have any effect on inflation expectations," he said. He expressed skepticism that inflation expectations have any independent impact on the actual inflation rate. "Inflation expectations still, as in the old days, depend on the actual outcomes of inflation, not on what somebody says inflation is about to be," he concluded.

James Hamilton suggested that Kocherlakota would presumably agree that the Federal Reserve could not reduce the unemployment rate by 4 percentage points within a two- to three-month horizon, but seemed persuaded that it could do so within a two- to three-year horizon, and that it had that power to do so in 2010. Hamilton asked what persuaded Kocherlakota that this was the case.

On the question of whether he necessarily believed that the FOMC could bring down unemployment in the next two to three years, Kocherlakota 
stated that the issue is really about both inflation and unemployment simultaneously. One would need to believe that in fact the FOMC did not have tools to bring either unemployment down or inflation up to 2 percent, and so one might as well just stop. He did not think that this really was the nature of the discussion in the FOMC at all, and it is not the nature of the models with which it works. The FOMC has the ability to affect inflation and unemployment separately, but it must carefully balance the tension between them.

In talking about timidity and the FOMC's sociology, Wolfers had stated, "It's hard to get 12 people to do radical things," referring to the FOMC's 12 members. In thinking about how an organization comes together to make decisions, what does "radical" mean? Kocherlakota noted that this was exactly the nature of the discussion during the Great Depression. In 1930, the FOMC wanted to tighten monetary policy because it had gone so far beyond the bounds of what was possible — of what was thought to be reasonable-for any right-minded person at that time. The FOMC's decisionmaking framework was described in terms of a reasonable setting for the policy instrument at a given point in time and with a given set of economic conditions. This mind-set framed the sense of what was radical. Kocherlakota advocated an approach practiced by Bernanke, which is for the committee to ask itself: Where are we? Where are we going? What are our forecasts? and How long is it going to take for us to get there? According to Kocherlakota, this is a much more reasonable way for the FOMC to think about what it is doing, as opposed to what should be done about interest rates or asset purchases at a given moment, which strict adherence to rules would require. He believed that if this had been the framing for discussions, as opposed to rules, it would have been much easier for people who are desperate for a framework to know how they should make a decision, and live up to their oath of office.

On the issue of how to think about a forecast-based framework as really being a rule, Kocherlakota stressed the importance of a time horizon. Simply stating that the goal is 2 percent inflation is not enough; the FOMC needs to talk about a time horizon over which it is planning to hit 2 percent. Kocherlakota was of the opinion that this had been missing from recent FOMC communications. If the FOMC is going to have a forecast-based framework, it is not enough to simply say, "Eventually we will. . . . Believe us, we'll get back to 2 percent," or "Unemployment will get back to maximal." He concluded that adding the element of a time horizon functions is a very disciplined way of enabling one to think about how to make monetary policy. 